\title{
Salivary Gland Neoplasia: A Review for the Practicing Pathologist
}

\author{
Richard J. Zarbo, M.D., D.M.D. \\ Henry Ford Hospital, Detroit, Michigan
}

The purpose of this review is to identify advances in salivary gland tumor pathology that have taken place over the past 30 years. In addition, selected tumor entities likely to be encountered or to present diagnostic difficulty in general practice will be addressed in detail.

\section{Epidemiology}

Over the years there has been some progress in clarifying specific causes of salivary gland cancer. The best known risk factor is that of radiation exposure as evident in the increased risk in atomic bomb survivors and in patients receiving therapeutic radiation. An increased occurrence in children with leukemias treated with multiagent chemotherapy and prophylactic cranial irradiation has also been noted (1). A dose response effect for low dose irradiation has been shown with a mean latency period of tumor development of 11 years for malignant tumors and 21.5 years for benign tumors (2). However, no increased risk is noted for exposure to UVB radiation.

Of potential viral etiologies, only EBV infection is implicated in the pathogenesis of salivary lymphoepithelioma-like carcinomas that are more commonly encountered in Eskimo and Chinese rather than Western populations. However, no increased risk is documented for infections with herpes, papilloma or HIV viruses $(3,4)$. Contrary to one previous study (5), it is acknowledged now that there is no increased risk of a second primary breast cancer in women who have had previous salivary gland cancer. However, there is some increased risk for the development of second primary cancers of the oropharynx, thyroid gland and lung, especially for those whose salivary gland cancers were treated with radiotherapy (6). Unlike other head and neck cancers, alcohol and smoking abuse are not asso-

Copyright (C) 2002 by The United States and Canadian Academy of Pathology, Inc.

VOL. 15, NO. 3, P. 298, 2002 Printed in the U.S.A.

Date of acceptance: September 27, 2001.

Address reprint requests to: Richard J. Zarbo, M.D., Department of Pathology, Henry Ford Hospital, 2799 W. Grand Blvd., Detroit, Michigan 48202; e-mail: rzarbo1@hfhs.org. ciated with increased risk for developing salivary gland neoplasms with the exception of a greatly increased risk and association of smoking with Warthin's tumor (7-9). One interesting finding, unconfirmed by others, is an elevated risk of salivary gland cancer in women employed as hairdressers and those working in beauty salons (10).

\section{Genetics}

Obviously, there are abnormalities based in the genome that underlie salivary gland neoplasia. This is evident in the rare familial autosomal dominant Turban Tumor (Brooke-Spiegler) syndrome, localized to a tumor suppressor gene on chromosome 16q12-q13. In this condition individuals develop numerous cutaneous dermal cylindromas, trichoepitheliomas and eccrine spiradenomas with occasional similar appearing (dermal analogue) salivary membranous type basal cell adenomas (11-13). Other salivary tumors known to have a familial occurrence include pleomorphic adenoma, acinic cell carcinoma (14), Warthin's tumor and lymphoepithelial carcinoma (15). The latter has also been noted in association with dominantly inherited trichoepitheliomas in a Finnish family (16).

Cytogenetic analyses of benign tumors show common abnormalities like trisomy 8 or translocations, often reciprocal, that involve activation of oncogenes HMGIC located on chromosome 12q13 and PLAG1 found on chromosome 8q12 (17). Recent evidence shows that PLAG1 is a nuclear protein that activates transcription of human insulin growth factor II (IGF-II) by binding to the promotor 3 site. Deregulation of this IGF-II target gene, inactive in adult salivary glands, is a recent molecular clue in salivary gland tumorigenesis (18). However, this does not appear to be specific to salivary gland as lipoblastomas also exhibit chromosome 8q12 rearrangements resulting in PLAG1 activation (19). Moreover, not all adenomas exhibit abnormal PLAG-1 expression leaving much about the role of oncogenes in tumor development and progression presently undefined. 
Genetic abnormalities common to the malignancies include trisomy 8 but also loss of genetic material like $\mathrm{Y}$ chromosome and deletion 6q21-23.3 and 6q27. It is hypothesized that these chromosomal abnormalities reflect inactivation of more than one tumor suppressor gene. Specific histologic tumor types are also associated with specific abnormalities -carcinoma ex pleomorphic adenoma [8q12-13 \& 12q13-15 rearrangements], adenoid cystic carcinoma (t[6;9][q21-24;p13-23]), and mucoepidermoid carcinoma (t[11;19] [q14-21;p12-13]) (17). Interestingly, the latter rearrangement is identical to that encountered in Warthin's tumor. With the advent of gene and protein expression profiling, future molecular and genetic insights are bound to influence current understanding of salivary gland tumorigenesis and its classification.

\section{Histogenesis versus Morphogenesis}

Much of the early years of salivary gland tumor pathology focused on relating histologic tumor types to cell of origin. The most popular histogenetic hypothesis championed by Batsakis and colleagues theorized two stem cell progenitors in proximal and distal regions of the duct system. A more hypothetical distal intercalated duct reserve cell was proposed as the progenitor of tumors with terminal ductal, myoepithelial and acinar differentiation whereas an excretory duct reserve cell was the proposed cell of origin for tumors with large duct, squamous or mucous cell differentiation (20, 21). A more recent progression in conceptualizing and classifying salivary gland tumors is a morphogenetic one, championed by Dardick (22), which relates morphology to cell differentiation derived from differential gene expression of a stem cell in conjunction with tumor matrix production rather than to a specific proposed cell of origin.

\section{Classification}

In the second half of the 20th century, the field of salivary gland tumor pathology proved fertile ground for the identification of a considerable number of new entities (Table 1). This is evidenced by the 16 salivary tumor entities listed in the 1954 AFIP fascicle classification of Foote and Frazell (23) compared with 36 entities in the 1996 AFIP fascicle authored by Ellis and Auclair (24). Since 1954 there has been a doubling in tumor categories of both benign (6 now 13) and malignant (10 expanded to 23). Classification schemes are dynamic, continuing to evolve as new light is shed on the biologic behavior of both established and newly described entities from clinical, pathologic, molecular and genetic studies so be prepared for continued evolution. Table 1 lists newly identified or named salivary
TABLE 1. Newly Identified or Named Salivary Gland Tumors since 1967

Basal cell adenoma (57)

Adenosquamous carcinoma (96)

Salivary duct carcinoma (91)

Sialadenoma papilliferum (97)

Epithelial-myoepithelial carcinoma (83)

Intraductal papilloma (98)

Membranous basal cell adenoma (11)

Malignant (metastasizing) myoepithelioma (90)

Inverted ductal papilloma (99)

Large cell undifferentiated carcinoma (100)

Lobular/terminal duct carcinoma $(69,70)$

Polymorphous low grade adenocarcinoma (68)

Low grade papillary adenocarcinoma-palatal (74)

Sialoblastoma (101)

Clear cell oncocytoma (102)

Dedifferentiated acinic cell carcinoma (36)

Basal cell adenocarcinoma (66)

Large cell neuroendocrine carcinoma (103)

Salivary gland anlage tumor (104)

Hyalinizing clear cell (intraductal) carcinoma (82)

Low grade salivary duct carcinoma (77)

High grade intraductal carcinoma $(78,79)$

gland tumors since 1967. Some, like basal cell adenoma, polymorphous low-grade adenocarcinoma, epithelial-myoepithelial carcinoma and salivary duct carcinoma have become important diagnoses in current surgical pathology practice.

\section{Pathology Report}

Despite the plethora of malignant salivary gland tumor types presented to pathologists for diagnosis, there is consensus on a limited number of pathologic observations that determine treatment and outcome and should therefore comprise the pathology report of salivary malignancies. The major points that should constitute all reports are 1) histologic type; 2 ) anatomic site of origin; 3 ) documentation of extent of disease to include information to allow TNM staging; 4) documentation of completeness of surgical excision and margin status. Documentation of anatomic site of origin is important as it often reflects differences in outcome of salivary gland malignancies but it is not clear whether this is because of biologic parameters innate to the location, advanced stage or secondary to ease of surgical extirpation with a clear margin. There is a trend for more favorable survival for cancers originating in intraoral and oropharyngeal minor salivary glands compared with major glands (parotid and submaxillary). The exception is the generally poorer survival for nasopharyngeal and paranasal sinus malignancies (25). Tumor stage and clinical/pathologic signs of local tumor aggressiveness are major predictors of distant metastasis and therefore ultimate outcome in salivary gland cancers of the parotid gland (26). 


\section{Tumor Stage}

Because of the diversity of head and neck anatomic sites in which salivary gland malignancies may arise, there is no single applicable stage system. For salivary gland cancers of the major glands (parotid, submaxillary, sublingual) there is a separate TNM clinical/pathologic staging system unified between the American Joint Committee on Cancer and the International Union Against Cancer (27). For minor salivary gland malignancies use of AJCC/UICC guidelines for squamous cell carcinomas occurring in the same regions of oral cavity/ oropharynx, nasopharynx and paranasal sinus sites has been shown to be a major outcome predictor by Spiro and colleagues (28). This was recently confirmed by Vander Poorten et al. who found no histopathologic or treatment parameters predictive of survival in minor salivary gland carcinomas but did affirm the prognostic value of $\mathrm{T}$ and $\mathrm{M}$ components of TNM classification (25). For the numerous head and neck sites, the $\mathrm{M}$ and $\mathrm{N}$ categories (exception nasopharynx) are the same but the specific pathologic assessments of the $\mathrm{T}$ categories vary (27). Therefore, in order to improve report completeness and quality, a synoptic/checklist design dedicated to salivary gland carcinomas would need to be customized for origin in minor glands by specific site of involvement (e.g., lip and oral cavity, pharynx, larynx, paranasal sinuses).

In all salivary gland malignancies it is important for the pathologist to completely document in the resection specimen the following to enable clinical staging, as specified in 1997 AJCC/UICC guidelines, to be pathologically confirmed:

1) For $\mathrm{T}$ component, aspects of size and local extension:

a. greatest tumor dimension in centimeters

b. extraparenchymal extension (major glands)

c. invasion of skull base or seventh nerve (major glands)

d. local extension/structures as per primary site TNM classification (minor glands)

2) For N component, aspects of number and size of positive nodes:

a. regional lymph node involvement documentation of single vs. multiple nodes

b. size of involved lymph node in centimeters

\section{Tumor Grade}

In general, histologic/cytologic grade is predictive of biologic behavior for salivary gland malignancies but lack of significance in survival studies compounded by issues of subjectivity and interobserver variation limit the influence of tumor grade. For the classic salivary gland malignancies, grading is not usually performed nor is there is any standard grading scheme applicable to all types. In most sali- vary gland cancers, the diagnostic classification itself indicates tumor grade. For instance, certain entities are acknowledged as low grade (polymorphous low grade adenocarcinoma, basal cell adenocarcinoma, acinic cell adenocarcinoma) and some as high grade (salivary duct carcinoma, adenocarcinoma NOS, squamous cell carcinoma, undifferentiated carcinoma, adenosquamous carcinoma).

\section{Grading of Adenoid Cystic and Mucoepidermoid Carcinomas}

Of the classic salivary type adenocarcinomas, two cancers, adenoid cystic carcinoma, mucoepidermoid carcinoma, exhibit a histologic spectrum in which grading is significant. One or more approaches have been proposed for these specific histologic types with some success. Grading schemes that appear to provide significant predictive insight into the biologic behavior of adenoid cystic carcinoma and mucoepidermoid carcinoma should be applied according to the schemes of Szanto (29) and Brandwein (30) modified after Auclair (31) and Goode et al. (32), respectively. In adenoid cystic carcinomas, the tubular and cribriform patterns are considered low grade with increasing admixed solid components contributing to higher grades 2 (greater than $30 \%$ solid) and grade 3 (predominantly solid) (Fig. 1). In mucoepidermoid carcinomas, the quantitative point scoring scheme considers the following parameters indicative of higher grade: intracystic component less than $20 \%$, presence of neural invasion or necrosis, mitotic rate of 4 or more per 10 high power fields and cellular anaplasia. The point scores result in three grades of low, intermediate, and high. Predictions of long-term biologic outcome by these two grading schemes are illustrated in Figure 2.

\section{Grading of Carcinoma ex Pleomorphic Adenoma}

Tortoledo et al. (33) and Brandwein and colleagues (34) have refined our understanding of biologic behavior of malignancies confined within (carcinoma in situ) and extending out from (carcinoma ex) pleomorphic adenomas. In the noninvasive (in situ) form, the behavior is similar to benign mixed tumor given complete surgical excision. For carcinomas ex pleomorphic adenoma, it is prognostically useful for the pathologist to measure extension of the carcinoma in millimeters beyond the capsule of the residual benign pleomorphic adenoma and to identify whether the malignancy is of low grade (e.g., polymorphous low grade adenocarcinoma ex pleomorphic adenoma). In the study of Tortoledo and colleagues, extension greater than 6 $\mathrm{mm}$ was predictive of a $70.5 \%$ recurrence rate compared with $16.5 \%$ recurrence for tumors extending 


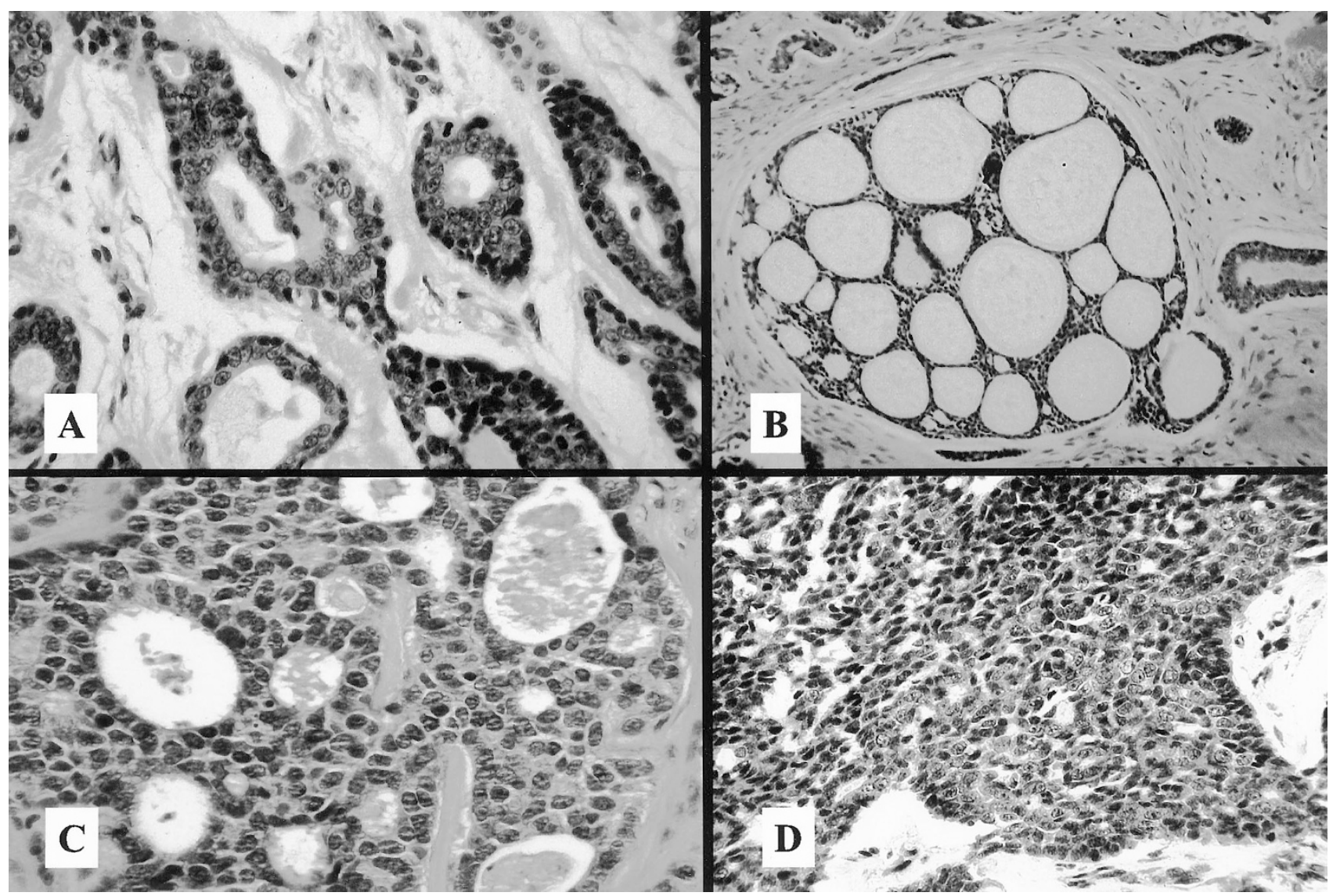

FIGURE 1. Grading of adenoid cystic carcinoma: low grade tubular pattern (A); low grade cribriform pattern (B); intermediate grade, partially solid (C); high grade solid (D).

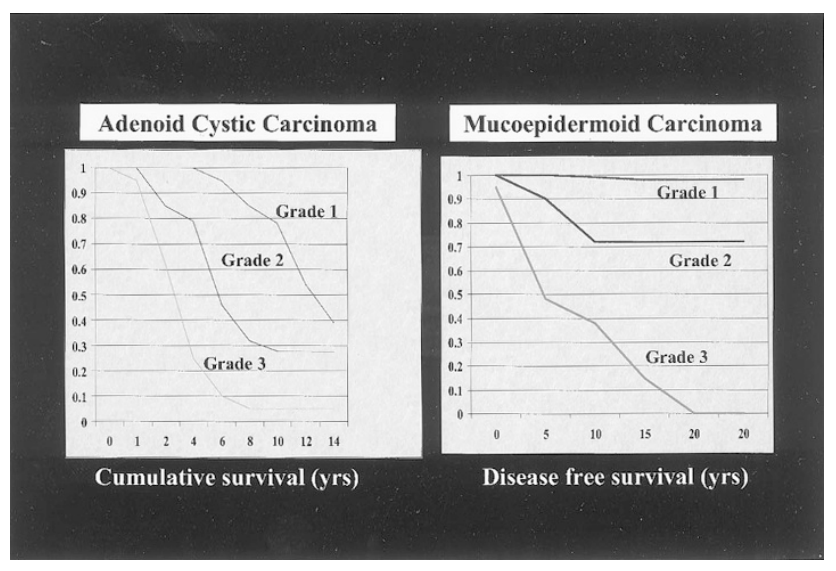

FIGURE 2. Influence of grade on long-term survival, applying the three-part grading schemes of Szanto and Brandwein to adenoid cystic carcinoma (left) and mucoepidermoid carcinoma (right), respectively.

less than $6 \mathrm{~mm}$. Moreover, of those carcinomas extending less than $8 \mathrm{~mm}$, there were no deaths from disease despite the presence of lymph node metastases (33). In the pathologic examination of benign mixed tumors, the finding of prominent zones of hyalinization, especially in larger tumors of the submandibular gland in older patients has been associated with a greater likelihood of malignant transformation (35). This morphologic marker of risk should dictate a complete sampling of the tumor to exclude malignancy.

\section{Grading of Adenocarcinoma NOS}

Many of the newly described entities listed in Table 1 were derived from this category of formerly unclassifiable tumors. Although current adenocarcinomas, not otherwise specified (NOS), show great diversity and there is no standardized grading scheme, I agree with the proposal that an attempt should be made to grade the unclassifiable cancers based on cytomorphologic features, usually in a three-tiered scheme (24). I have found it convenient to apply a simple nuclear grading scheme rather than the more detailed approaches to grading of breast ductal carcinomas that consider tubule formation and mitotic activity as well. It is likely that the diverse neoplastic types still comprising the category of adenocarcinoma NOS will likely be a fruitful source of newly identified tumor types or tumors bearing specific markers indicative of biologic behavior. A good rule of thumb is that if a salivary gland adenocarcinoma does not nicely fit previously described entities, and a metastasis can be excluded, then adenocarcinoma NOS is the appropriate diagnosis. 


\section{Dedifferentiated Carcinoma}

The concept of dedifferentiation in salivary tumor pathology is essentially the identification of the clonal evolution of a poorly differentiated or high grade element arising within a low-grade carcinoma. This was first described in 1988 by Stanley and colleagues who reported six cases of acinic cell carcinoma that contained areas of poorly differentiated adenocarcinoma or undifferentiated carcinoma without histologic transition or a spectrum from the acinic cell element. These cases were clinically aggressive exhibiting significant nerve symptoms of pain, paresthesia, or facial paralysis and pathologically widely invasive with early metastasis (36). This concept is to be contrasted with malignancy arising from a benign tumor (prototype carcinoma ex pleomorphic adenoma) and the rare hybrid tumors in which divergent differentiation results in two or more different tumor entities that arise simultaneously within the same topographical area (e.g., acinic cell carcinoma and salivary duct carcinoma) (37).

In a dedifferentiated tumor, the anaplastic component may be juxtaposed to or located within the original tumor but morphologically the original line of differentiation is "lost" or a new line of differen- tiation is expressed. This phenomenon may be considered either de novo transformation to another distinct tumor type (e.g., undifferentiated carcinoma arising in epithelial-myoepithelial carcinoma or myoepithelial carcinoma arising in adenoid cystic carcinoma) or histologic transformation to a higher grade element within the low-grade carcinoma (e.g., undifferentiated carcinoma arising within polymorphous low grade adenocarcinoma). This is distinguished from histologic transformation within a high-grade carcinoma to another high-grade pattern, as in sarcomatoid salivary duct carcinoma (38). Dedifferentiation has been documented in acinic cell carcinoma (Fig. 3), mucoepidermoid carcinoma (39) adenoid cystic carcinoma (40), polymorphous low-grade adenocarcinoma (41) and epithelial-myoepithelial carcinoma (42). The histologic patterns may be sharply demarcated or blended within the low grade tumor in varying proportions with various appearances that have included glandular, squamous, polygonal cell, spindle cell and undifferentiated forms. Dedifferentiation has been noted $a b$ initio or at recurrence, often post radiation therapy. These morphologic observations are significant and portend clinical aggressiveness but molecular mechanisms of dedifferen-

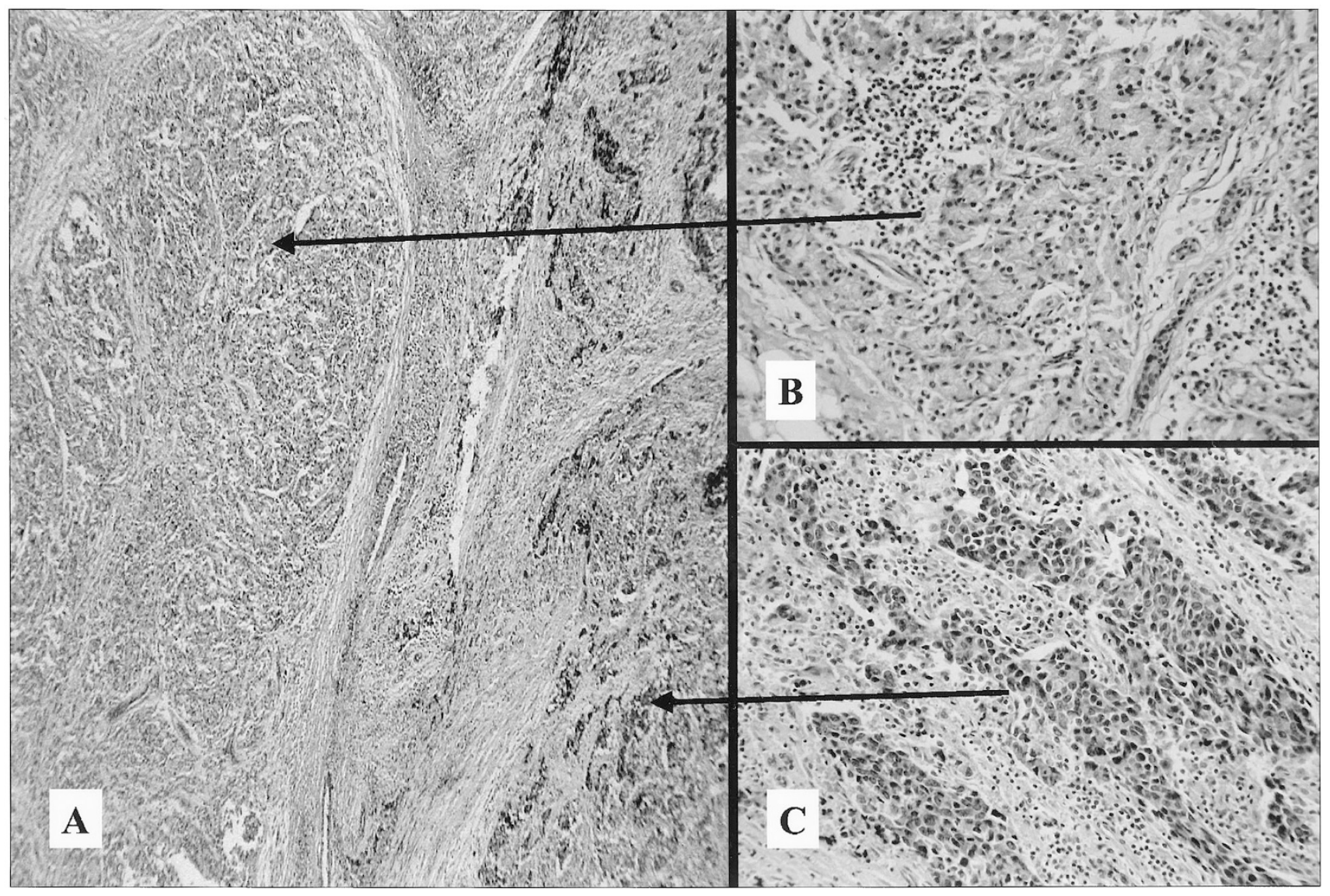

FIGURE 3. Dedifferentiated acinic cell carcinoma with clear demarcation (left) of well differentiated acinic cell component shown at high power (upper right) and poorly differentiated element (lower right). (Case provided courtesy of Dr. Douglas Gnepp.) 
tiation in salivary gland neoplasia are yet to be clarified. The potential for dedifferentiation in many types of low-grade salivary gland cancers would dictate that complete sampling should be the standard approach to all salivary gland tumors encountered at the gross bench.

\section{New Techniques}

Salivary gland tumors have been the subject of most of the new techniques. This would include flow cytometry DNA/SPF analysis, immunoproliferation markers PCNA and Ki-67, nucleolar counts (AgNORs) and assessments of oncoproteins p53 and Her/2. However, these characterizations can be considered preliminary and are presently of no clinical utility. The interpretations are confounded by issues of short follow-up, prolonged natural history of the disease, small sample size due to rarity of salivary gland tumors and lack of method standardization (17). The current surgical pathology approach to salivary gland tumor diagnosis and characterization is a morphologic one with limited use of immunohistochemistry in select differential diagnoses, complemented with
TABLE 2. Antibodies that May Be Helpful in Resolving Difficult Differential Diagnoses

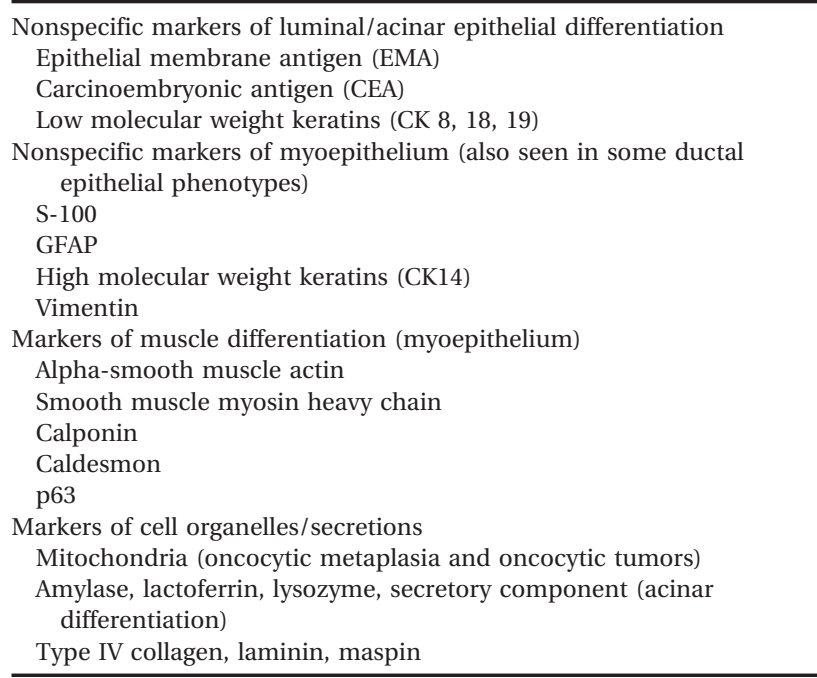

time tested pathologic staging and documentation of margins.

\section{Immunohistochemistry}

There are few absolutes in salivary gland tumor diagnosis given the marked spectrum and overlap

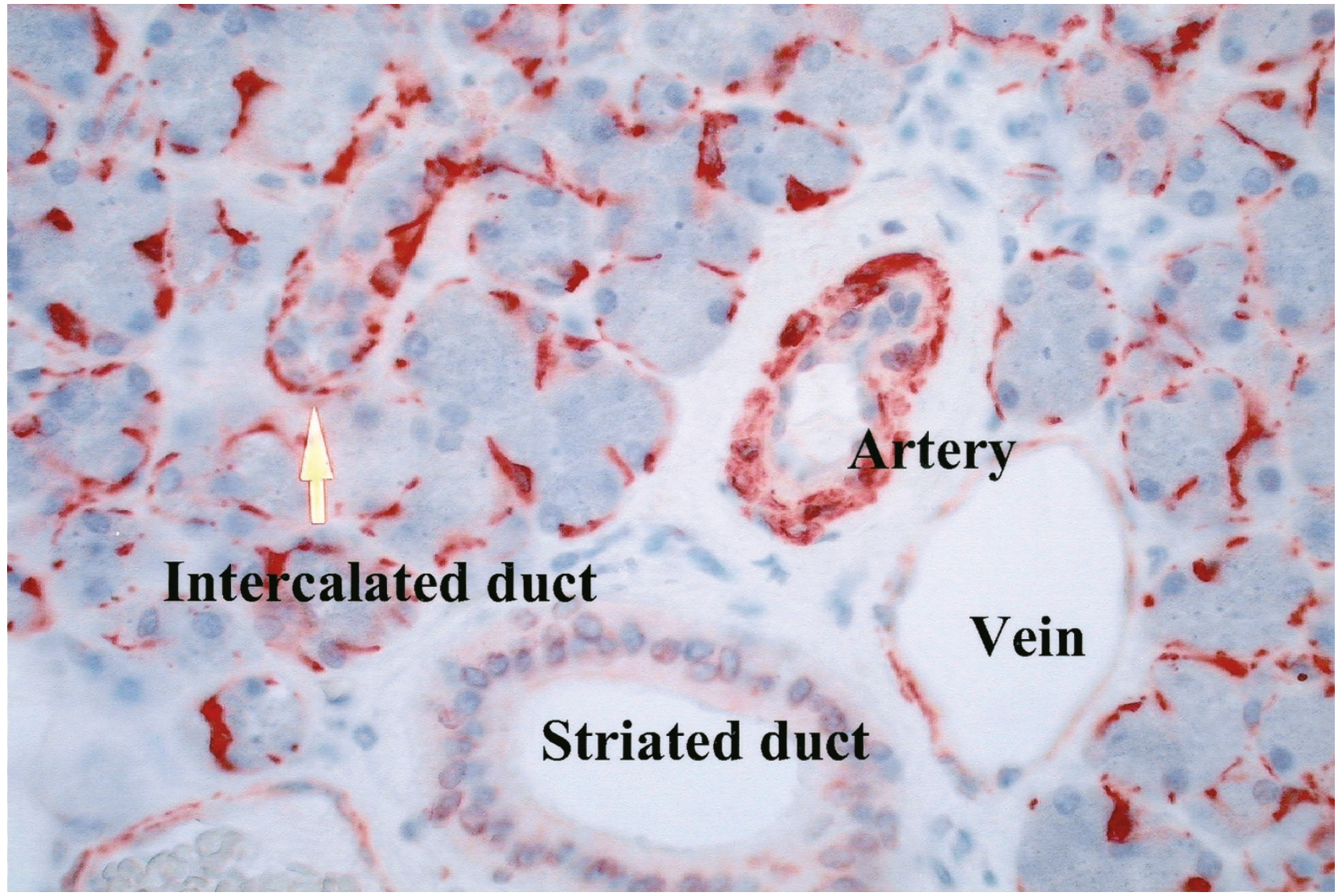

FIGURE 4. Calponin immunohistochemical staining of normal salivary gland defines tapered and triangular shaped myoepithelial cells surrounding acini and intercalated ducts (arrow). Also outlined are smooth muscle cells of an artery and vein. Striated duct is unstained. 
of differentiated cell types that participate in the numerous benign and malignant tumors. Having said that, Table 2 enumerates antibodies that may be helpful in resolving difficult differential diagnoses when applied with astute morphologic correlation (43-51). Many immunohistochemical investigations have pursued differentiation markers, especially of myoepithelium, to assist in classification. The first antibodies applied, directed to S-100 protein, vimentin and GFAP, have been found to be nonspecific in their reactivity. However, there is promise for some of the newer myoepithelial smooth muscle markers like alpha smooth muscle actin, smooth muscle myosin heavy chain, calponin (Fig. 4), caldesmon and p63 in select diagnostic situations $(46-49,52,53)$. This would include the identification of neoplastic myoepithelium in bilayered tubules, cribriform structures or in spindled and myxoid stroma in pleomorphic adenomas, variants of basal cell adenoma and adenocarcinoma, adenoid cystic carcinoma, epi-myoepithelial carcinoma, and noninvasive low-grade salivary duct carcinoma. These stains are also confirmatory of broad morphologic range of myoepithelial differentiation in the epithelioid, spindled, clear cell and plasmacytoid morphologic variants of myoepithelial carcinomas. Markers like EMA and CEA have been used to indicate acinar or glandular differentiation and selective markers for organelles, such as mitochondria, may be useful in selective differential diagnoses of oncocytic tumors (50). Other salivary secretions like amylase, lactoferrin, lysozyme, secretory component and cell matrix components type IV collagen, laminin and maspin can be detected by immunohistochemistry but have not found a diagnostic role. In general, immunohistochemistry as an ancillary diagnostic tool should be used sparingly and wisely as a morphologic adjunct because of the lack of specificity of many markers for specific histologic tumor types.

\section{Role of Myoepithelium}

In the future there may be some role for the pathologic assessment of myoepithelial differentiation in salivary gland tumor types, as there appears to be a modifying effect of this cell type on biologic behavior. For instance, during development myoepithelium induces salivary gland morphogenesis and epithelial differentiation. This cell also appears to resist neoplastic transformation. In the neoplastic state, myoepithelium has a lower proliferation than basal type epithelial cells and secretes excess substances that inhibit tissue invasion and metastasis. These accumulated myxoid ground substances and basement membrane components as well as numerous proteinase inhibitors like maspin, a-1-antitrypsin, TIMP-1 and protease nexin II all contribute to an anti-invasive matrix for myoepithelial-rich salivary gland tumors (54). For example, myoepithelial carcinomas exhibit lobulated and pushing rather than infiltrative tissue growth patterns and prolonged survivals despite distant metastasis (49). There is also some indication that myoepithelium may inhibit angiogenesis, further contributing to local growth and inhibition of metastasis (55). These factors may relate to the lobulated, pushing, hypovascular invasive character and prolonged survivals despite distant metastasis attributed to tumors like epithelial-myoepithelial carcinoma and myoepithelial carcinoma. Much further study is needed before observations of this nature could be translated clinically.

\section{Review of Tumor Entities}

I have elected to discuss and illustrate the morphology of a number of benign and malignant salivary gland tumor entities that the practicing pathologist will encounter. These have been selected because they readily simulate each other but have very different clinical therapies and therefore should be included routinely in differential diagnosis.

\section{Salivary Gland Adenomas}

The salivary gland adenomas can be considered to represent a morphologic spectrum of differentiation (Fig. 5). At the midpoint lie the more commonly encountered pleomorphic adenomas whose proliferation of epithelial ducts and myoepithelial derived stromal appearances, have been shown to be monoclonal in original based on PCR analysis of the human androgen receptor gene (56). Therefore, it is the matrix production and mesenchymal morphologic metaplasia resulting in the "mixed" ap-

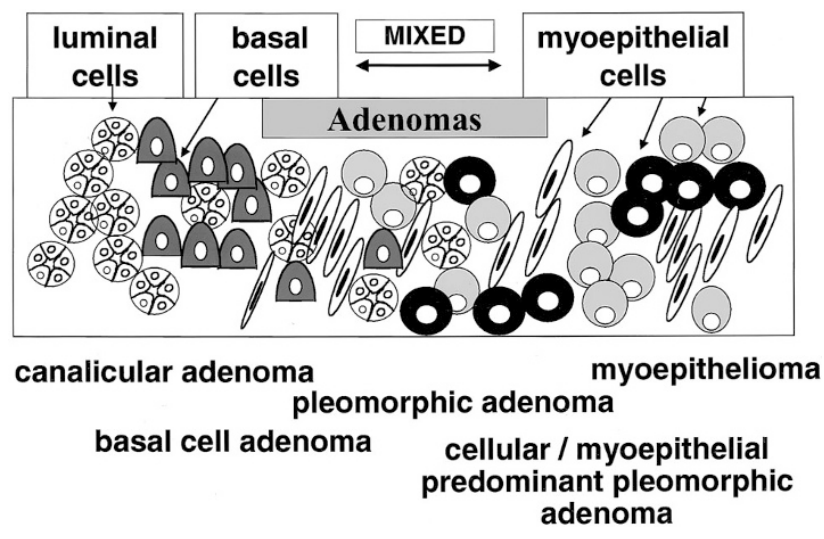

FIGURE 5. Schematic diagram depicting the overlapping cellular differentiation comprising the morphologic spectrum of the salivary gland adenomas. Pure ductal luminal differentiation (canalicular adenoma) depicted on the left with increasing degrees of myoepithelial participation in basal cell adenomas and pleomorphic adenomas progressing to pure myoepithelial differentiation (myoepithelioma) on the right. 
pearance that distinguishes this classification from other so-called basal cell adenomas and the rare myoepitheliomas. Whereas the myoepithelial component in the basal cell adenomas is usually histologically inapparent without the use of immunomarkers and matrix is lacking, by definition the myoepitheliomas are composed only of myoepithelial cells that may assume various and mixed morphologies but may exhibit some hyalinized and myxoid matrix production as well. At the far end of the adenoma spectrum lie benign tumors composed purely of tubular cells, the canalicular adenomas.

\section{Basal Cell Adenomas}

The basal cell adenomas were first named by Kleinsasser and Klein (57) in 1967 and formally recognized in the WHO classification in 1991 (58). This category excludes canalicular adenoma, which was formerly called a basal cell adenoma and is more common in the oral cavity. The basal cell adenomas are rare, accounting for $1.5 \%$ of all epithelial and $2.4 \%$ of all benign salivary gland tumors in the AFIP registry (24). Most occur in the major glands ( $75 \%$ parotid, $5 \%$ submaxillary gland) of adults (mean age 58 years) with a 2:1 female predi- lection. With the exception of the membranous type, they are solitary and circumscribed. These tumors are treated by conservative excision and have demonstrated a low recurrence rate. Also, with the exception of the membranous type there is a $4 \%$ rate of malignant transformation. Most malignancies arising from basal cell adenomas are of the basal cell type with rare nonbasaloid carcinomas reported (59).

The morphologic subtypes encompassed by the term basal cell adenoma may look quite different histologically. The most common is the solid type, followed by the trabecular and trabecular-tubular types, the membranous and the rare tubular types (Fig. 6). All have a fibrous stroma and lack a myxochondroid matrix as in pleomorphic adenoma. The trabecular-tubular variant, however, exhibits subtle stromal spindled cellularity that has been shown to be of myoepithelial origin, underscoring the relationship to pleomorphic adenoma $(43,44,60)$. All variants may demonstrate cystic change, squamous whorls, frank keratinization or rare cribriform patterns. The common proliferation is that of uniform, cytologically bland basaloid cells with occasional palisading at the periphery. Darker basaloid cells are noted at the periphery of nests with larger, paler

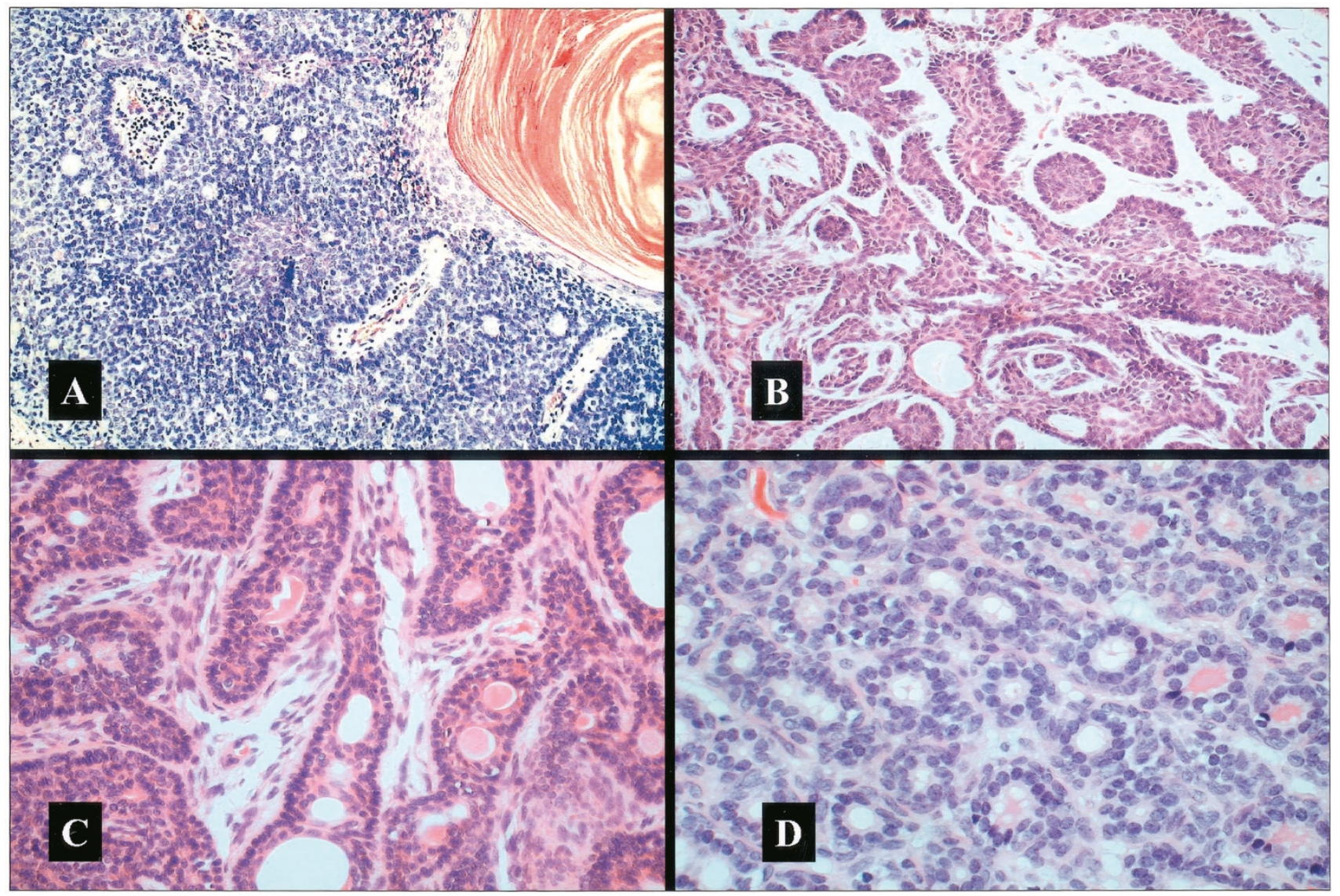

FIGURE 6. The solid (A), trabecular (B), trabecular-tubular (C), and tubular (D) morphologies encompassed by the term basal cell adenoma. 
cells in central areas. There is myoepithelial differential in all of the morphologic patterns of basal cell adenoma which is inapparent morphologically but has been recently demonstrated with antibodies to smooth muscle proteins (Fig. 7) (46).

\section{Membranous Adenoma}

The membranous type of adenoma, also know as the dermal analogue tumor, was first described in 1977 by Headington and colleagues $(11,12)$. It occurs mainly in the parotid gland or may arise in a parotid lymph node thereby simulating a metastasis. This tumor may be associated with the autosomal dominant salivary gland-skin adnexal tumor syndrome (Brooke-Spiegler). Cutaneous tumors have been reported in $25-38 \%$ of individuals with membranous adenomas of salivary gland $(61,62)$. These individuals may develop hundreds of dermal cylindromas, trichoepitheliomas and spiradenomas that are morphologically mimicked by the salivary gland cylindroma-like adenomas (dermal analogue). A rare case of an intranasal salivary type membranous adenoma occurring in this syndrome has also been described (63).
Histologically, basaloid nests and islands of cells forming jigsaw patterns that are surrounded by a prominent hyalinized reduplicated basement membrane and may have coalescent membrane droplets within characterize the tumor (Fig. 8). Cystic change and squamous metaplasia may be seen in larger solid nests.

Roughly half of the membranous adenomas are multifocal and most are unencapsulated. These two features in conjunction with the cylindroma-like patterns with hyalinized basement membrane and occasional origin within parotid lymph nodes may simulate malignancy, especially adenoid cystic carcinoma. However, the latter demonstrates a higher degree of cytologic atypia with hyperchromatic angular nuclei or vesicular nuclei with distinct nucleoli and true cribriform patterns associated with a basophilic matrix.

Membranous adenomas have a fairly high rate of recurrence $(25 \%)$ and malignant transformation (28\%) (64). Malignant transformation is recognized histologically as a destructive infiltrative basaloid growth beyond the confines of the gland or perineural or vascular invasion. Malignancy need not

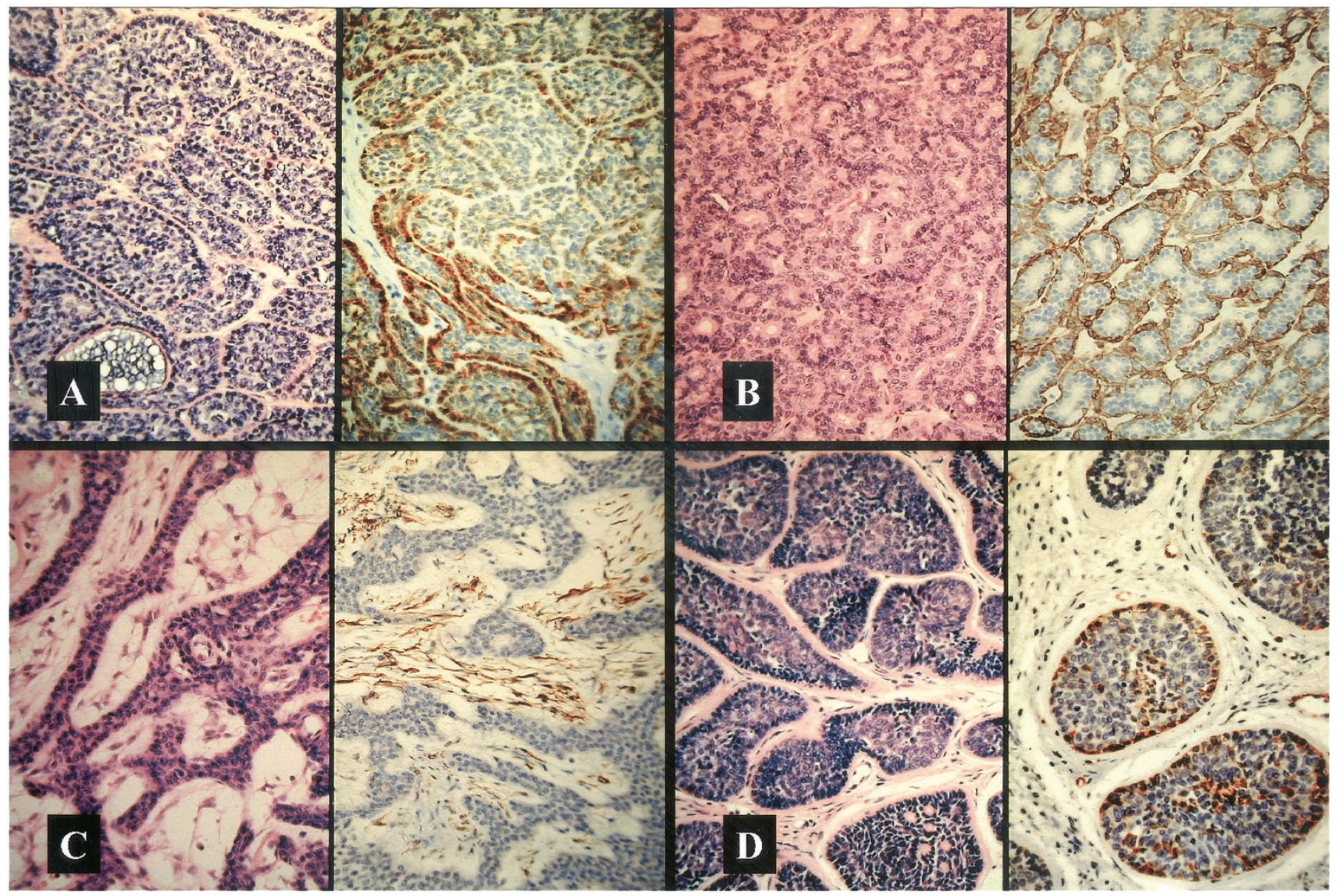

FIGURE 7. Myoepithelial differentiation identified by immunostaining for calponin in solid (A), tubular (B), trabecular-tubular (C), and membranous (D) basal cell adenomas. Note the positively stained spindled stromal cells of the trabecular-tubular adenoma (C) indicating myoepithelial derived stroma similar to that found in pleomorphic adenoma. 


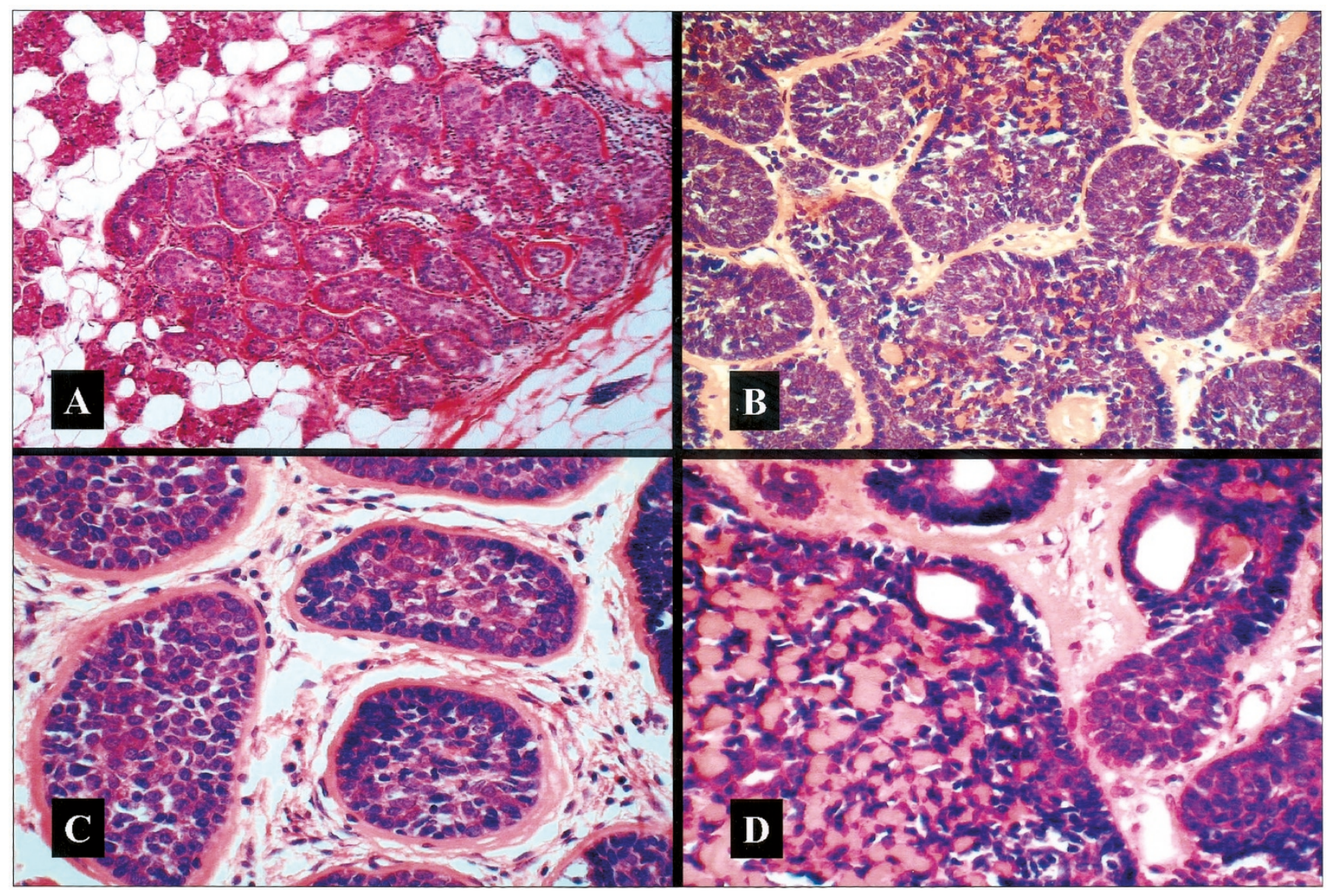

FIGURE 8. Membranous adenomas present worrisome features due to unencapsulation and, often, multifocality (A). Tumors are distinguished by basaloid nests forming jig-saw patterns (B), surrounded by prominent hyalinized reduplicated basement membrane (C), with coalescent membrane droplets within cell nests (D).

be associated with pleomorphism, necrosis or mitotic activity in these tumors. This will be discussed further under basal cell adenocarcinoma.

\section{Canalicular Adenoma}

The canalicular adenoma (Fig. 9) has been a recognized entity since the 1950s and was formerly designated basal cell adenoma. It is typically encountered as an intraoral minor salivary gland tumor usually in the upper lip or buccal mucosa of individuals over age 50 with a female predominance. Clinically the tumor is perceived as a superficial, painless, compressible, slow growth. Canalicular adenomas account for roughly $1 \%$ of all salivary gland tumors and $4 \%$ of all minor salivary gland tumors (24).

Microscopically, this tumor is usually encapsulated but roughly $22 \%$ are multifocal (65). It is composed of lines of columnar ductal-luminal cells rather than basal type cells that form branching double rows (canaliculi) that come together intermittently (beading) and may undergo cystic change. The intervening stroma is characteristically parvicellular, edematous and finely vascular. Mixed solid trabecular and adenoid basal cell patterns that overlap with basal cell adenomas may be seen but do not change the biologic behavior or the immunophenotype of S-100 protein positive and focally GFAP positive but muscle marker negative cells (43, 44, 46). However, these patterns in conjunction with the multifocal appearance may invoke additional differential diagnoses of trabecular adenoma, basal cell adenocarcinoma or adenoid cystic carcinoma. Adenoid cystic carcinoma is the most critical to identify because of differences in treatment and outcome. Although occasionally circumscribed, it would demonstrate true destructive infiltration, cribriform patterns, bilayered ducts and strong immunoreactivity for muscle markers.

It is not uncommon for the pathologist to receive these tumors as fragmented specimens likely due to the cystic nature of many canalicular adenomas. Despite the appearance of having been "shelled out" so that margin assessment is compromised, recurrence is uncommon.

\section{Basal Cell Adenocarcinoma}

Basal cell adenocarcinomas are low grade malignancies so named in 1990 by Ellis and Wiscovitch (66). These tumors were previously recognized over 


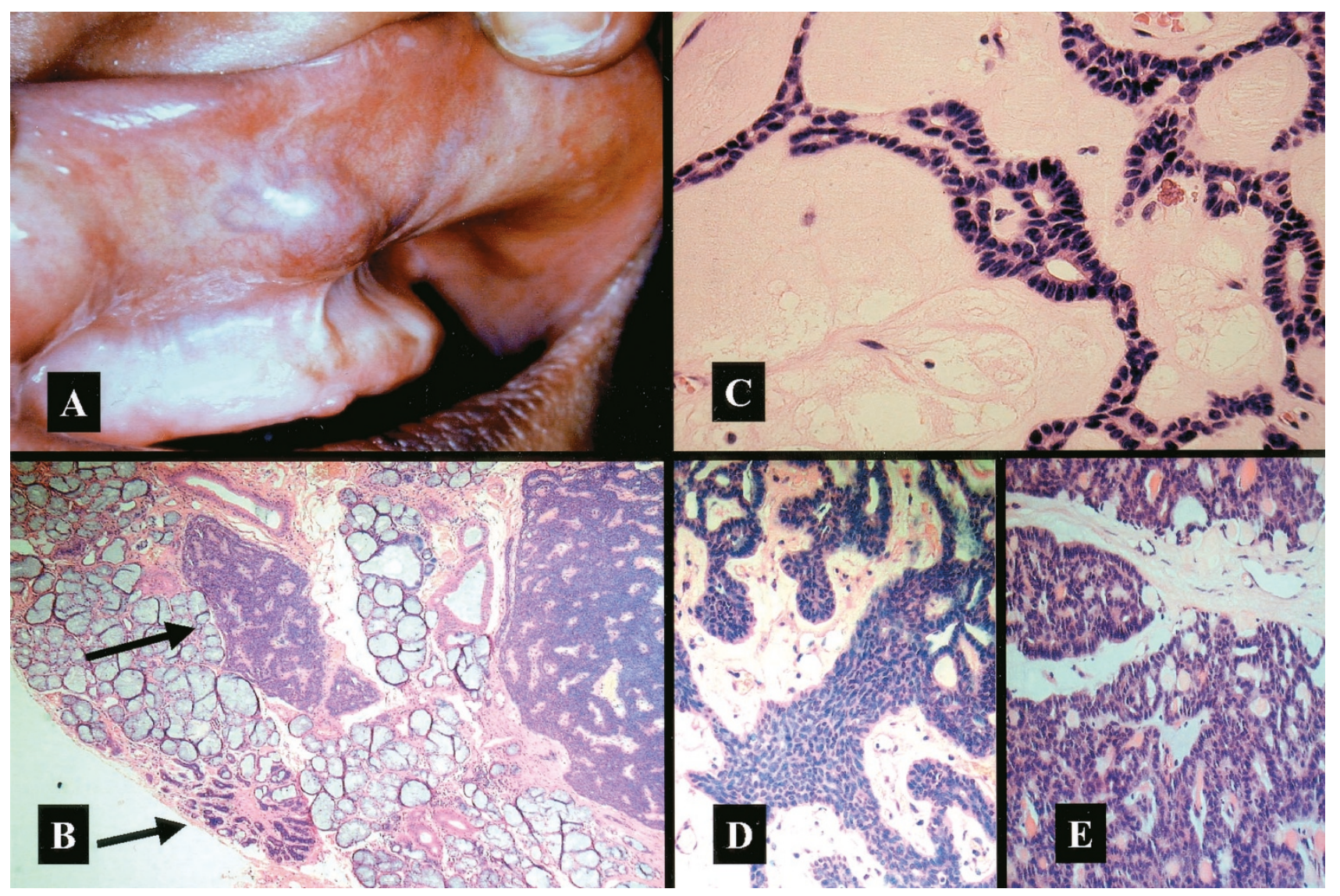

FIGURE 9. Canalicular adenomas present typically in the upper lip, here of an edentulous female (A). Multifocality (B) may be encountered in roughly a quarter of cases. Typical histology (C) of branching canaliculi of columnar cells forming double rows with intermittent "beading" set in a parvicellular, edematous and finely vascular stroma. Variations may include mixtures of trabecular (D) and adenoid (E) basal cell patterns raising additional differential diagnoses but no differences in behavior or immunostaining profile.

the years with various labels like basaloid carcinoma, hybrid basal cell adenoma, adenoid cystic carcinoma, carcinoma arising out of monomorphic adenoma and even sialoblastoma. The basal cell adenocarcinomas are rare, accounting for $1-2 \%$ of epithelial salivary malignancies. They usually occur in adults, average age 60 , with no gender predilection. All but one case reported in the palate have been in the major glands, mostly the parotid. Roughly $77 \%$ arise de novo with $23 \%$ arising within preexisting basal call adenomas. About $10-14 \%$ of basal cell adenocarcinomas are associated with the skin adnexal tumor syndrome (67).

Basal cell adenocarcinomas exhibit the same cytology and patterns as the basal cell adenomas but these growths are malignant as judged by destructive local infiltration, neural and vascular invasion, lymph node metastasis and rarely distant pulmonary metastasis.

Histologically these tumors are often multicentric (63\%) with patterns that are single or mixed solid, trabecular, tubular and membranous and lack myxoid or myxochondroid matrix (Fig. 10). The latter feature is helpful in discrimination from basaloid type pleomorphic adenomas. To date only the solid pattern of basal cell adenocarcinoma has metastasized (67). These basaloid tumors may be cytologically bland or may exhibit some degree of pleomorphism, increased mitoses, proliferative Ki-67 and apoptotic indexes compared with the adenomas. However, these measures are not helpful in the individual case because of the overlap with the adenomas of similar pattern. Therefore the diagnosis is based on infiltration and invasion of neural and lymphovascular spaces. These features distinguish basal cell adenocarcinomas from similar appearing unencapsulated, multifocal membranous adenomas that don't show destructive infiltrative growth or perineural or vascular invasion.

Basal cell adenocarcinomas are treated conservatively with the intent of clear margins. These are low-grade malignancies with only one patient of 45 with follow-up in the review of Muller and Barnes who died of disease. From that review there is a local recurrence rate of $37 \%$, an $8 \%$ rate of metastasis to cervical lymph nodes (four cases), only two cases (4\%) with metastasis to lungs (67).

The chief differential diagnosis is that of adenoid cystic carcinoma which may share the solid, tubular and cylindroma-like patterns (Fig. 11). Often help- 


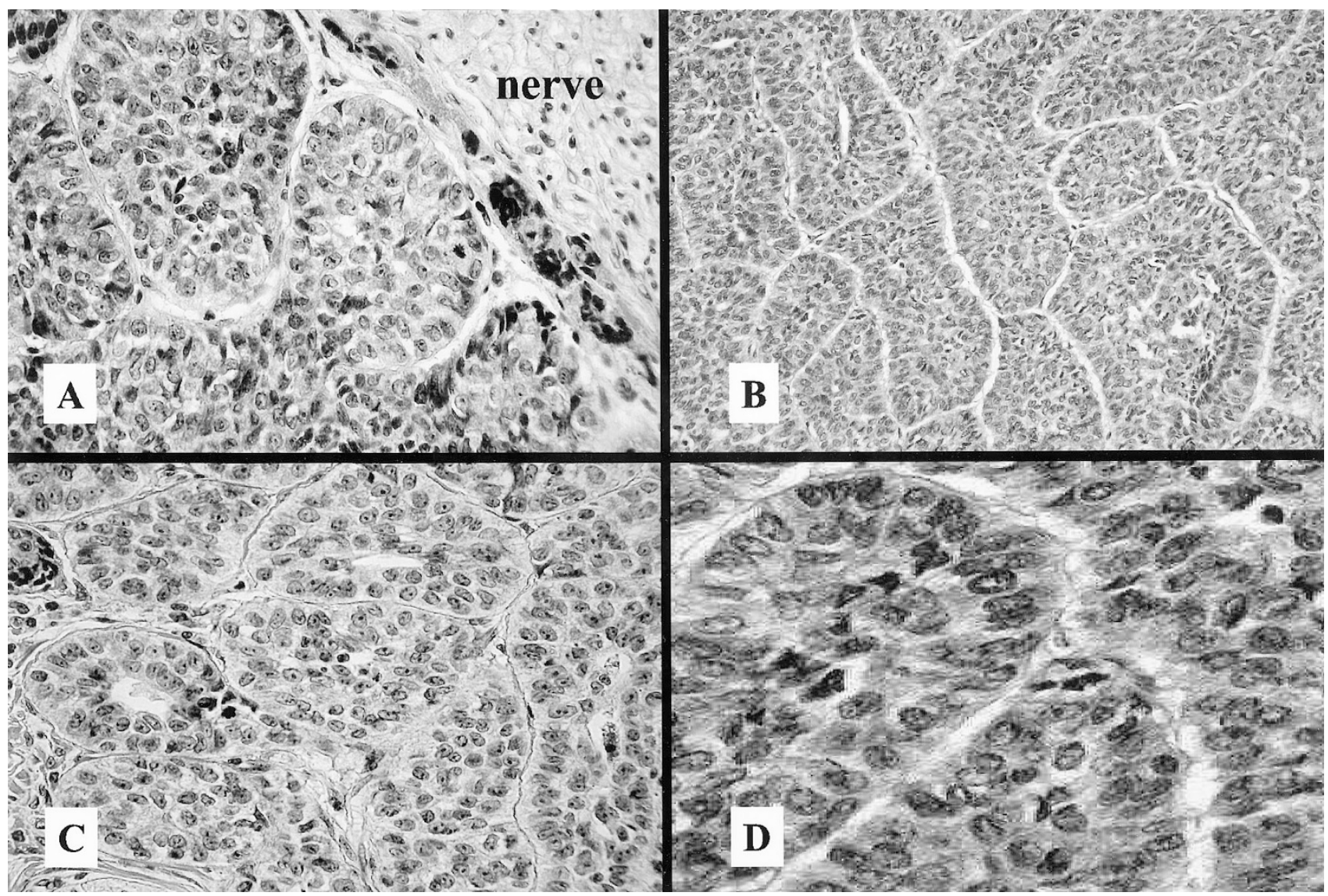

FIGURE 10. Basal cell adenocarcinomas are distinguished from basal cell adenomas by local infiltration (A) but share the same histologic patterns, here solid (B) and tubular (C) patterns illustrated. The cytology is typically bland (D) and may not show increased pleomorphism and mitotic activity compared with the adenomas.

ful are the presence of true cribriform structures and bilayered ducts with intense immunostaining for muscle markers in conjunction with the character of the nuclei in adenoid cystic carcinoma that are either angular and hyperchromatic or vesicular with prominent nucleoli.

Also a consideration is the infiltrative, solid, basaloid components of polymorphous low-grade adenocarcinomas (Fig. 11). The cytologically bland PLGA however have numerous histologically diverse low-grade patterns, which are characteristic and discussed in greater detail next. In addition adenosquamous carcinomas may have fields that are basaloid, but also may have true mucous cells, a neoplastic squamous component and associated carcinoma in situ of the overlying mucosa. Basaloid squamous carcinomas may also have a neoplastic squamous component and a pseudoglandular appearance with accumulation of a hyaline matrix but these cancers exhibit a significant degree of anaplasia compared with basal cell adenocarcinomas (Fig. 12). Small cell carcinoma, primary or metastatic, may also be considered in the complete differential diagnosis of a basaloid salivary neoplasm (Fig. 12). Powdery chromatin, indiscernible nucleoli, spindled cells, nuclear molding, high mitotic rate, crush artifact, single cell necrosis, and cytokeratin dots or neuroendocrine differentiation by immunohistochemistry are often helpful. Lastly, basaloid variants of ameloblastoma may resemble the cytologically bland basal cell salivary gland adenomas and adenocarcinomas as well but demonstrate peripheral palisading and polarization of columnar cells and an edematous stellate reticulum-like epithelium within the tumor nests (Fig. 12).

\section{Polymorphous Low Grade Adenocarcinoma (PLGA)}

Polymorphous low-grade adenocarcinoma is the name coined in 1984 by Evans and Batsakis to describe a morphologically diverse histologic spectrum of intraoral adenocarcinomas of similar lowgrade cytology and biologic behavior (68). In the previous year a more restricted histologic entity, now incorporated into PLGA, was described as terminal duct carcinoma by Batsakis et al. and also recognized as lobular carcinoma by two oral pathologists, Freedman and Lumerman $(69,70)$. Although the oral cavity, especially the palate, is the typical site of involvement, rare cases have been reported in the nasal cavity and nasopharynx (71). 


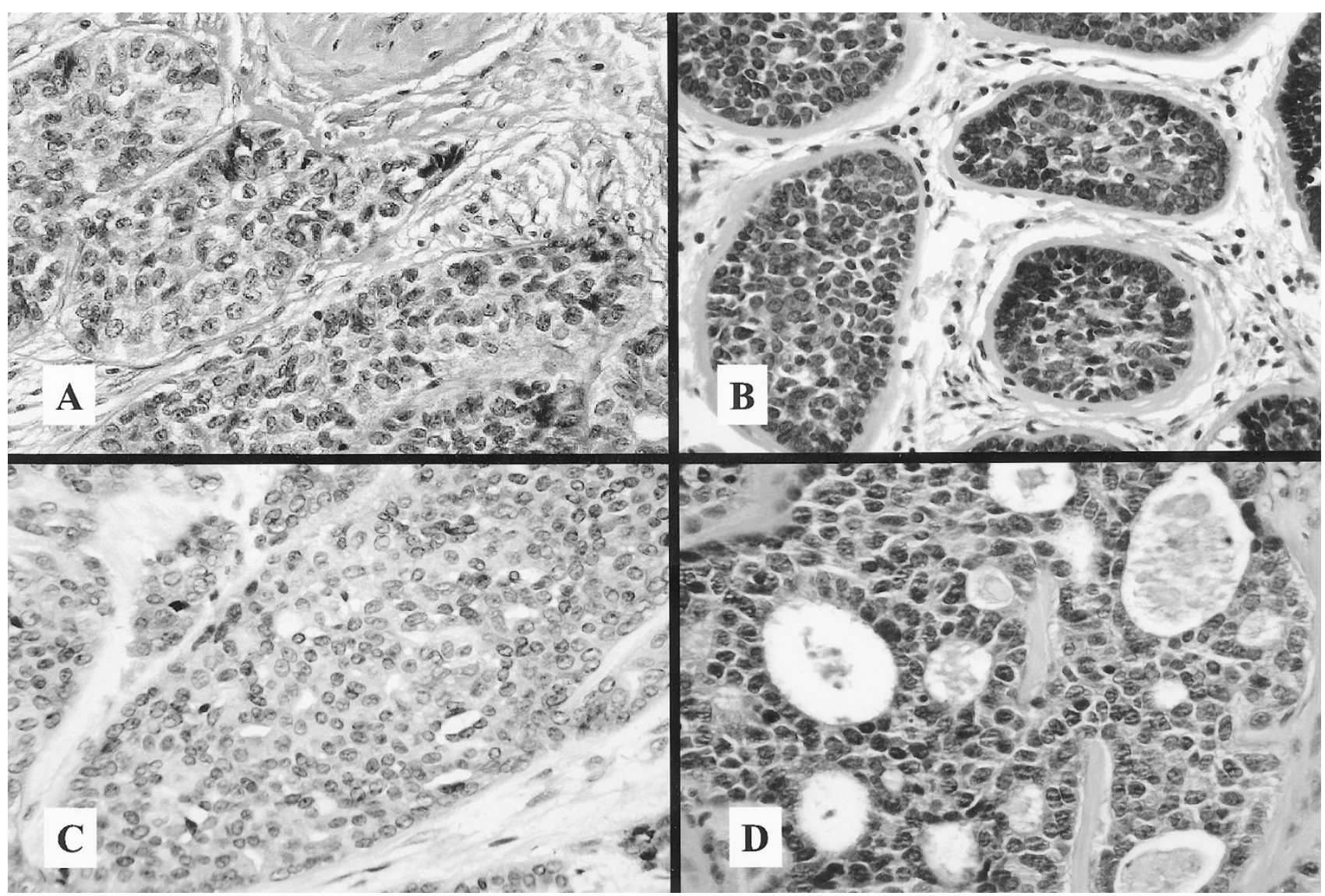

FIGURE 11. Chief differential diagnosis of basal cell salivary neoplasms: basal cell adenocarcinoma (A); membranous adenoma (B); polymorphous low-grade adenocarcinoma (C); adenoid cystic carcinoma (D).

In the major glands, PLGA may be observed as a low grade carcinoma arising from a pleomorphic adenoma (33). PLGA occurs over a wide age range with a peak in the 7 th decade and a 2:1 female predilection (72). In my experience PLGA have been more common than adenoid cystic carcinomas in the oral cavity.

Although they are often well circumscribed, PLGA are infiltrative neoplasms that may extend into muscle, bone, cartilage and commonly nerves. All histologic patterns are cytologically uniform and bland, characterized by vesicular ("open") nuclei with stippled chromatin and inconspicuous to small nucleoli (Fig. 13). Mitotic figures are rare and necrosis not seen. What distinguish PLGA are the mixtures of polymorphous growth patterns. These include solid (jigsaw), cribriform (pseudoadenoid), tubular (usually a single cell layer) (73), trabecular, fascicular (streaming), linear single cell (indian file), and cystic patterns (Figs. 14, 15). The proliferations are often centered on a nidus, commonly a focus of perineural invasion, lending a targetoid appearance. PLGA are only focally papillary, so an extensive papillary component should raise the possibility of the more aggressive low-grade palatal papillary adenocarcinoma $(74,75)$ or papillary cys- tadenocarcinoma with its well developed papillae and fibrous cores. Also potentially complicating interpretation is that the stroma may be fibrous, mucoid or hyaline in appearance, not unlike that of adenoid cystic carcinoma. A characteristic slate gray-blue stroma also may mimic the mucoidmyxoid matrix of pleomorphic adenoma (72). PLGA stain strongly for EMA and S-100 protein but only focally for GFAP and muscle markers (Zarbo unpublished observations) (43, 44, 72).

Because of morphologic diversity and histologic overlap, cases of PLGA are most likely to be misdiagnosed as pleomorphic adenoma. The likely scenario is a small incisional biopsy that does not reflect the heterogeneous patterns or infiltrative nature and perineural invasion of PLGA or contains focal stromal change simulating a myxochondroid matrix. A fact worth filing is that pleomorphic adenomas of minor salivary gland are not often encapsulated and may have focal extensions into adjacent minor salivary gland that are seemingly infiltrative when interpreted in a narrow field context. A low power appreciation of the circumscribed nature of pleomorphic adenomas of minor salivary gland compared with the widely infiltrative nature of PLGA and common perineural invasion are use- 


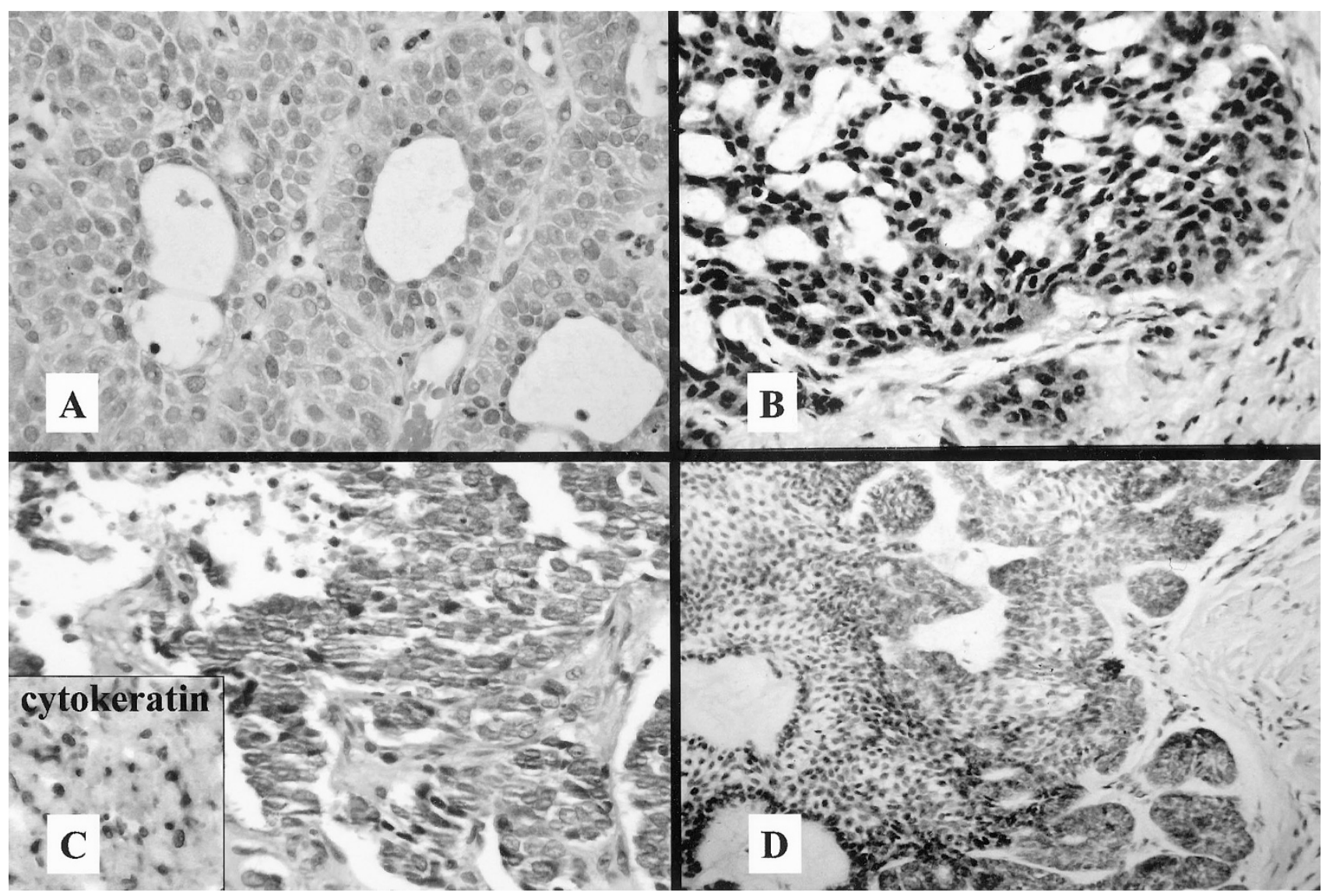

FIGURE 12. Additional neoplasms with basal cell features: adenosquamous carcinoma (A); basaloid squamous cell carcinoma (B); small cell carcinoma (C), inset cytokeratin dots; basaloid ameloblastoma (D)

ful histologic discriminants as is the intense staining of pleomorphic adenoma for muscle markers of myoepithelial differentiation.

The differential diagnosis also commonly includes adenoid cystic carcinoma because of common cribriform, tubular and solid growth patterns and perineural invasion. However, unlike PLGA, the tubules of ACC are always bilayered rather than composed of a single layer, there is significant degree of nuclear atypia and immunostaining for muscle markers demonstrates intense staining indicative of myoepithelial differentiation.

PLGA are indolent neoplasms that are unlikely to cause death. The recurrence rate from a literature review and a large AFIP series is $9-17 \%$, of those $40 \%$ were multiple recurrences $(72,76)$. Roughly $9 \%$ of PLGA have metastasized to regional lymph nodes. In the study of 164 cases, by Castle and colleagues, $97.6 \%$ of patients were either alive or had died of unrelated causes without evidence of disease with an average follow-up of 115.4 months (72). To date, only one case of a biopsy proven distant metastasis to lung has been documented (72). Unlike adenoid cystic carcinoma, PLGA are treated by conservative wide excision. Therefore it is especially critical to diagnose a PLGA rather than adenoid cystic carcinoma in any location but most notably in the palate as the latter diagnosis would result in a more radical excision of the hard palate.

\section{Intraductal Carcinoma of Salivary Glands}

Ten cases of low-grade ductal carcinoma in situ were described in 1996 by Delgado, Klimstra, Albores-Saavedra as low grade salivary duct carcinoma. These were tumors in the parotid gland of adults, one of which had stromal microinvasion (77). Of six patients with follow up, none with low grade salivary duct carcinoma have had any further evidence of disease. Four cases of high grade intraductal carcinomas were previously reported by Anderson et al. (78) and Chen (79) in major and minor salivary glands. Total parotidectomy appears to be the therapy of choice as subtotal resection was followed by multiple recurrences in one case and progression to invasive ductal carcinoma in another.

Low grade intraductal carcinomas are unencapsulated but circumscribed yet multifocal. On gross examination the mass is focally to diffusely cystic. Microscopically ducts that retain the native myoepithelial cell layer exhibit partial to circumferential 


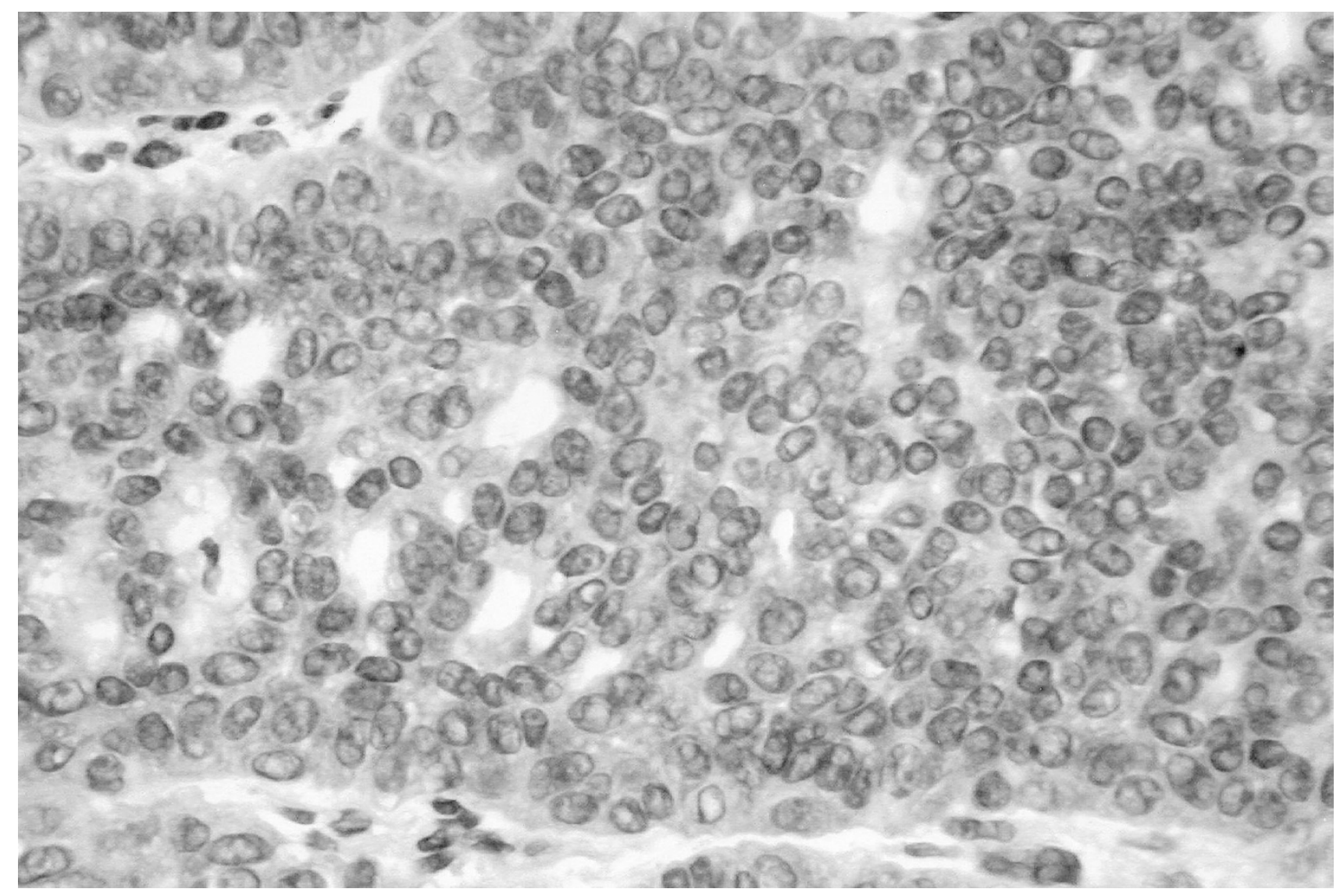

FIGURE 13. Polymorphous low grade adenocarcinomas of all histologic patterns share low grade cytology with uniform, bland vesicular "open" nuclei with inconspicuous nucleoli.

intraductal proliferations that mimic patterns of atypical ductal hyperplasia to carcinoma in situ of breast with micropapillary, tufted, solid or fenestrated patterns (Fig. 16). The cytology is bland composed of ductal, apocrine or vacuolated cells with rare mitoses and no necrosis. Focal high-grade cytologic atypia was noted in one case. By immunohistochemistry the epithelial cells stain strongly for S-100 protein, high molecular weight cytokeratin and mark for gross cystic disease fluid protein 15 in areas of apocrine differentiation. As in breast DCIS, the lesion must be well sampled and it may be useful to apply muscle markers of myoepithelium to rule out microinvasion.

The main differential diagnosis is that of salivary duct carcinoma. This is an aggressive, invasive ductal carcinoma that also mimics breast cancer and has a mean survival of 3 years. The ductal patterns of this high-grade cancer may bear a range of cytologic atypia, commonly have comedo necrosis and are truly invasive with irregular profiles, lacking a myoepithelial cell layer. The intraductal cribriform patterns may simulate adenoid cystic carcinoma but lack the small basaloid cells, hyaline membranes and pseudocystic spaces containing basophilic matrix material. Also a consideration is the papillary cystic variant of acinic cell carcinoma in which zymogen granules can be demonstrated by the periodic acid-Schiff-diastase stain. Because of low-grade cytology, PLGA may be entertained in differential diagnosis but origin in minor not major glands and the multitude of infiltrative patterns are distinctive. The intracystic proliferations in papillary cystadenoma/cystadenocarcinoma differ in that the papillae are well developed with fibrous cores lined by atypical, mitotically active cells.

\section{Clear Cell Carcinomas}

Although this heterogeneous collection of salivary gland cancers with clear cytoplasm may be illustrated as a continuum, this is not a biologically proven concept (Fig. 17). At one end of the spectrum are monomorphic epithelial proliferations of clear cells, which may have associated hyalinized stroma (hyalinizing clear cell carcinoma) or nonhyalinized stroma and exhibit glandular or squamous differentiation or remain undifferentiated. These clear cell carcinomas stain for the markers of epithelium- CEA, EMA but are negative for the muscle markers indicative of myoepithelium. Previously, they have also been termed glycogen-rich squamous carcinoma and glycogen-rich adenocarcinoma $(80,81)$. 


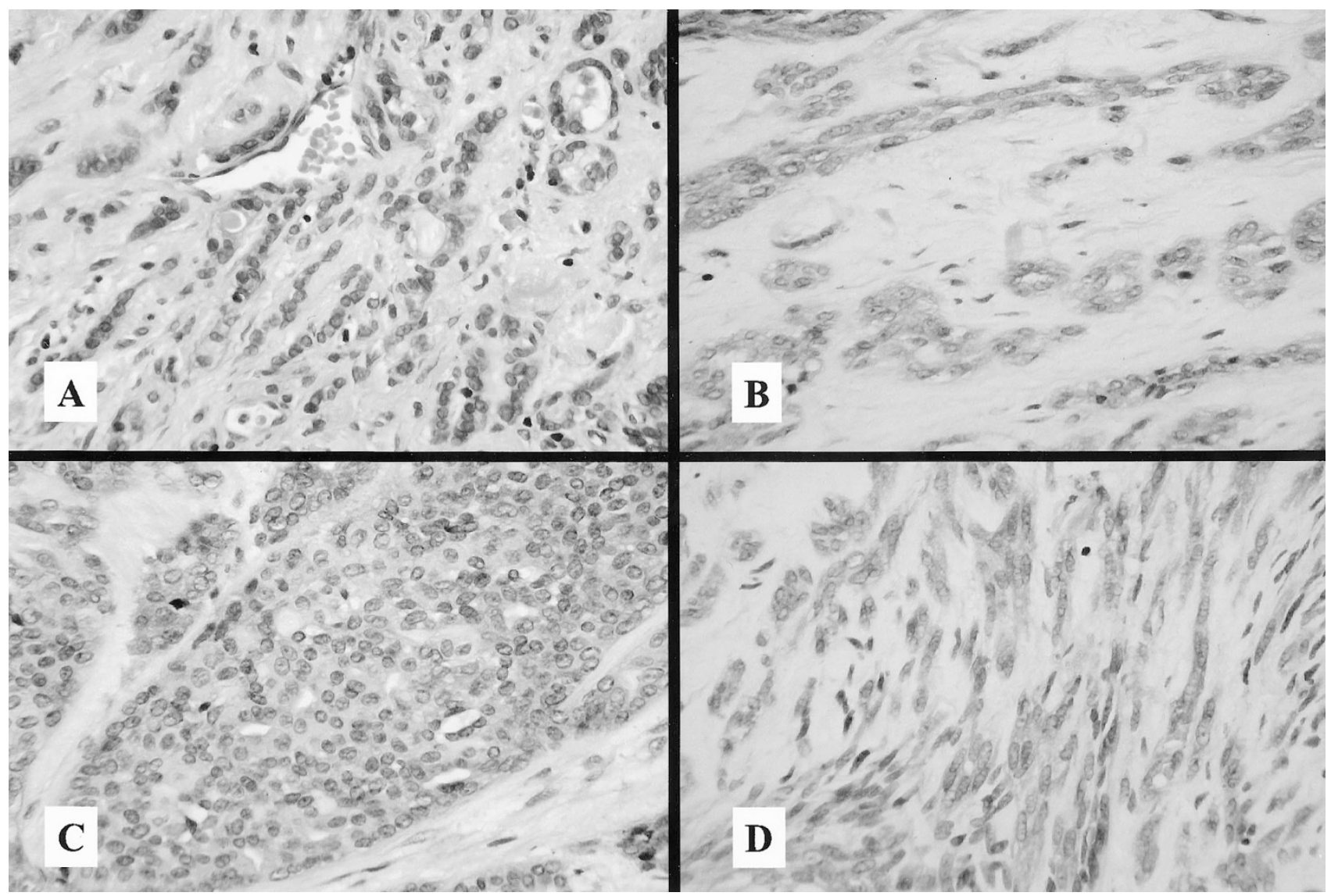

FIGURE 14. Polymorphous low grade adenocarcinoma histologic patterns: linear single cells (indian file) (A); tubular (B); solid (C); fascicular (streaming) (D).

Clear cell carcinomas also include the bimorphic cancers named epithelial- myoepithelial carcinomas, composed of recognizable tubules cuffed by neoplastic, clear myoepithelial cells that may also predominate. These bimorphic clear cell neoplasms exhibit their dual morphology both at the light microscopic and immunophenotypic level. They have also been called adenomyoepithelioma, glycogen rich adenoma and glycogen rich adenocarcinoma.

At the other end of the spectrum are monomorphic proliferations of clear cells that are purely myoepithelial in nature and designated clear cell myoepithelial carcinoma. They stain for myoepithelial markers, especially S-100 protein and the muscle markers.

In the differential diagnosis of these three identified forms of salivary clear cell carcinomas, consideration should be given to clear cell variants of other salivary tumor entities like mucoepidermoid carcinoma, acinic cell carcinoma and sebaceous carcinoma. Lastly, metastatic renal cell carcinoma is often a consideration. Its S-100 protein and muscle marker negative phenotype is like that of the monomorphic epithelial clear cell carcinomas but can be excluded on clinical grounds and the pres- ence of hypervascularity, hemorrhage, necrosis and a combined vimentin-cytokeratin phenotype.

\section{Hyalinizing Clear Cell Carcinoma}

Hyalinizing clear cell carcinoma is the designation coined in 1994 by Milchgrub and colleagues for 11 cases of glycogen rich clear cell carcinomas of low-grade biologic behavior that had an associated hyalinized stroma. These cases involved mostly intraoral minor glands, the majority in the base of tongue and palate, with a female predilection, but also the parotid gland, larynx and subglottis (82).

On histologic examination, solid masses, nests, infiltrating cords and single file cells may be composed of either glycogen rich clear cells of mild cytologic atypia or smaller cells with eosinophilic cytoplasm (Fig. 18). Mitoses are rare. The degree of stromal hyalinization varies within fields of the same tumor, may not be present at all and therefore perhaps just the simple designation clear cell carcinoma fits best. It is probable that this category contains several clear cell, glycogen rich salivary gland neoplasms representing squamous and glandular differentiation and possibly subtle myoepi- 


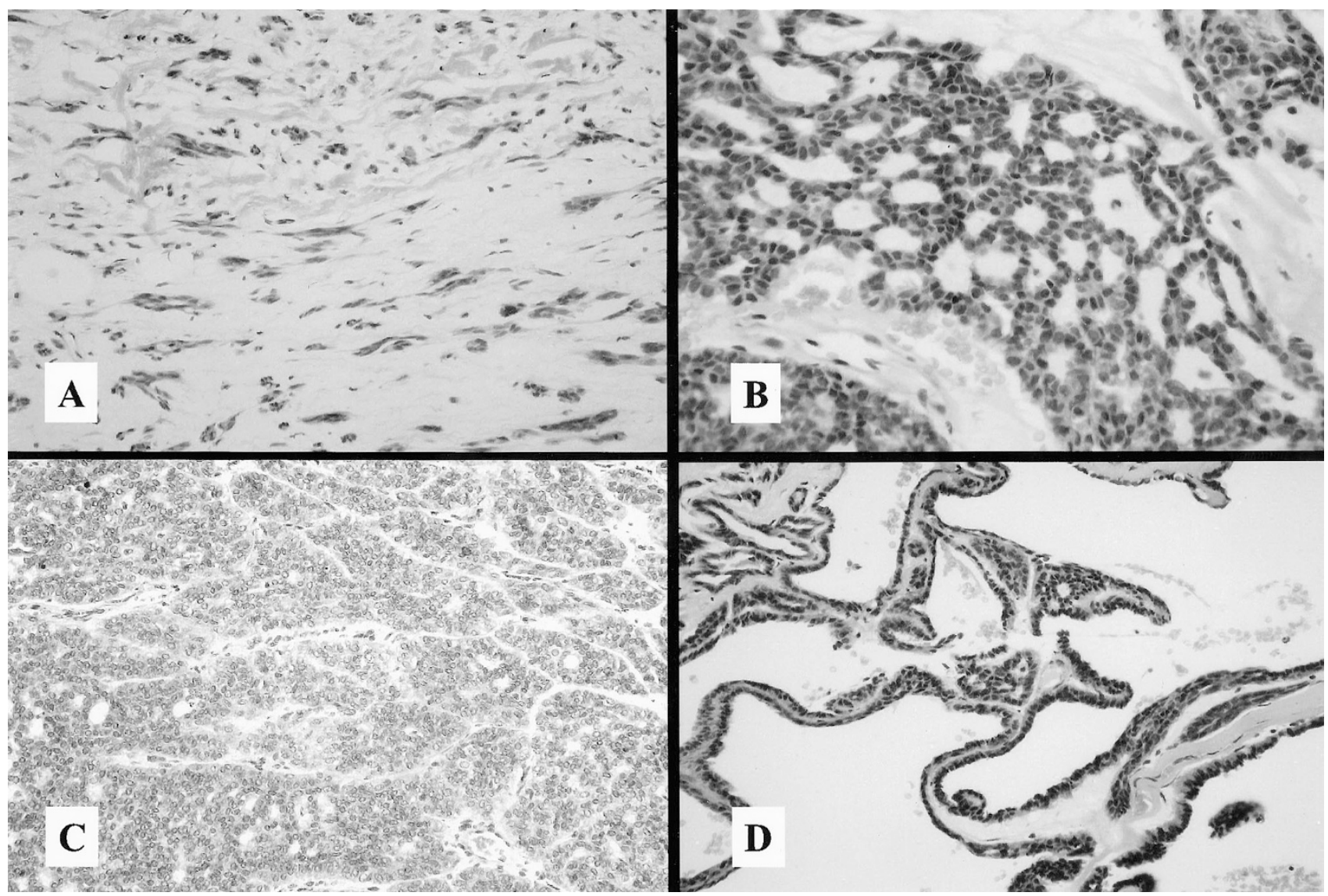

FIGURE 15. Additional polymorphous low grade adenocarcinoma histologic patterns: myxoid (A); cribriform (pseudoadenoid) (B); jigsaw (C); cystic (D).

thelial differentiation unappreciated with current techniques.

Since the initial report of 11 cases, I have identified an additional five cases reported with rare tumors described in the nasopharynx and centrally within jaws (83-85). At this time, no patients have died from disease but follow-up has been relatively short given the prolonged nature of many salivary gland cancers. Based on 13 cases with follow-up, there is a recurrence rate of $8 \%$ (one case originating in the nasopharynx) and a $15 \%$ rate of metastasis to regional lymph nodes (two intraoral cases). Given the small numbers and follow-up, knowledge of the long-term biologic behavior is somewhat limited so expect this entity to evolve.

\section{Epithelial-Myoepithelial Carcinoma}

Epithelial-myoepithelial carcinoma (EMC) was first described in 1972 by Donath, Seifert and Schmitz in the German literature (86) and recognized by the World Health Organization in the 1991 classification (58). It is a rare entity that usually involves the parotid gland but may arise in the other major glands (submaxillary and sublingual) as well as the minor glands of the oral, nasal and paranasal cavities. EMC typically affects adults in the 7 th decade of life with a slight female predominance.

Although well circumscribed grossly, most cases demonstrate infiltrative margins and perineural invasion. In the classic form there is a double cell proliferation composed of an inner layer of neoplastic ductal cells that are associated with an outer layer of prominent clear neoplastic myoepithelial cells. Also described are a sclerotic (hyalinizing) variant and a clear cell dominant variant (ductal poor), where the epithelial cells forming the ducts are inapparent (Fig. 19). The potential for dedifferentiation is also recognized in this entity $(42,87)$.

EMC has been historically considered a lowgrade malignancy as reflected in the $39 \%$ recurrence rate and $8.5 \%$ death rate in the MD Anderson series of nine cases reported by Luna and colleagues (88). More recently, Fonseca and Soares who followed up 20 cases of EMC and showed a cumulative survival of $87.1 \%$ at 5 years and $67.5 \%$ at 10 years have challenged this notion (89). Moreover, in this series the $41 \%$ recurrence, $35 \%$ metastatic rate, and $40 \%$ rate of death from disease suggests that with long-term follow-up, the biologic behavior of EMC may be better appreciated as an intermediate grade malignancy. 


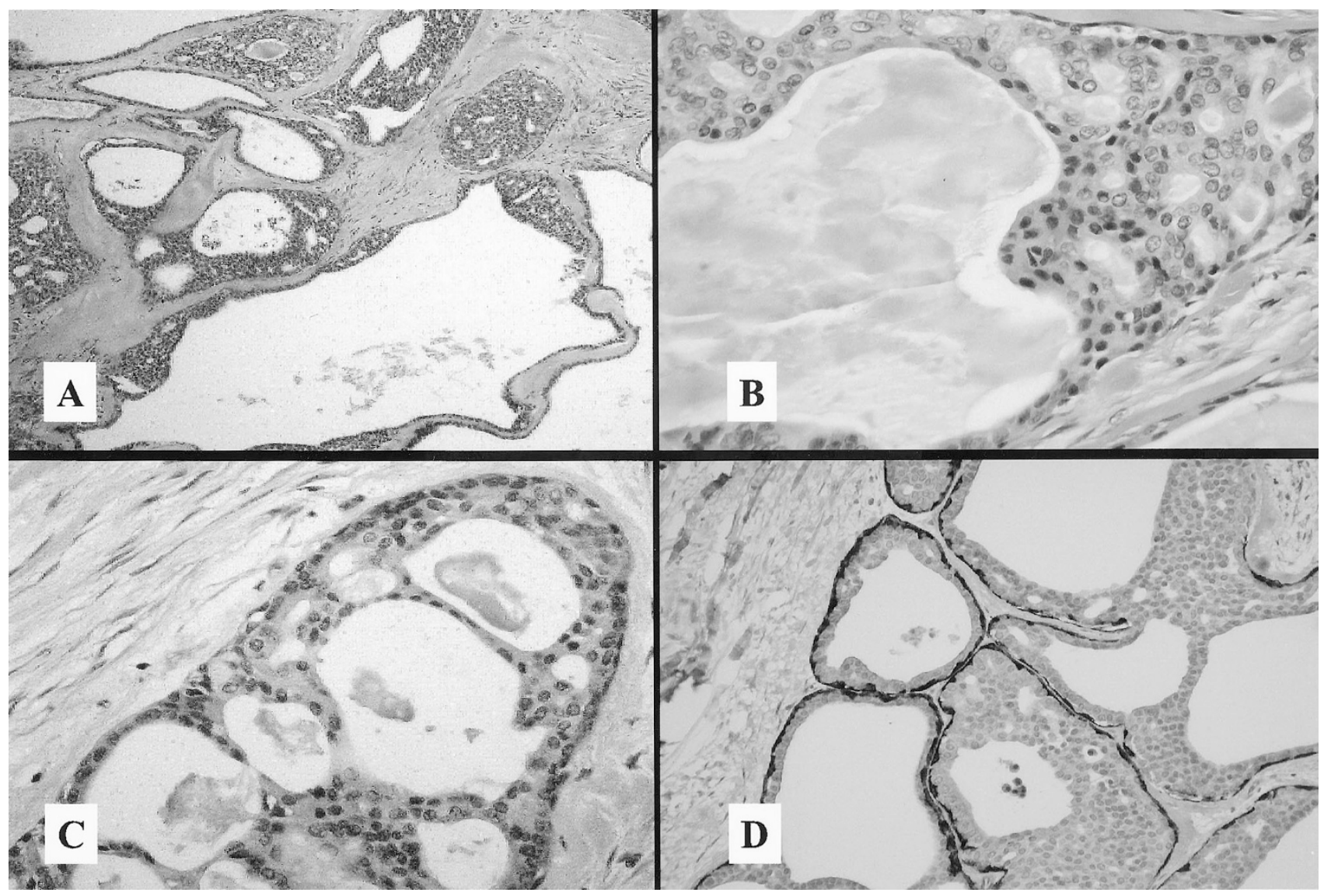

FIGURE 16. Low grade (in situ) salivary duct carcinoma forming an unencapsulated but circumscribed mass lesion in the parotid gland (A). Intraductal proliferations (B, C) mimic patterns of atypical hyperplasia and low grade DCIS of breast. Despite the florid proliferation, a retained myoepithelial cell layer can be demonstrated with immunostains to smooth muscle specific proteins, here calponin (D), to rule out microinvasion.

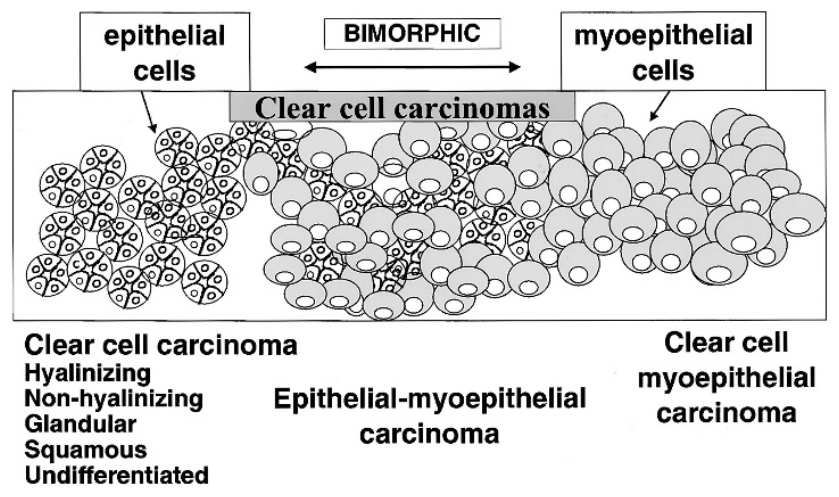

FIGURE 17. Schematic diagram shows the morphologies and differentiated cell types comprising the salivary gland clear cell carcinomas with monomorphic epithelial and monomorphic myoepithelial carcinomas at either end and bimorphic epithelialmyoepithelial carcinomas in between. Although a useful taxonomic illustration, this is not a biologically proven continuum and no interrelationships are intended.

\section{Clear Cell Myoepithelial Carcinoma}

Few clear cell carcinomas of purely myoepithelial differentiation have been reported involving the major glands $(49,90)$. They may exhibit various histologic appearances with tight nests, hyalinized cords, trabeculae, vacuolated-signet ring cell-like and lipoblast-like morphologies (Fig. 20) but more commonly are seen mixed with other histologic manifestations of myoepithelial carcinoma, discussed next. Four cases of clear cell myoepithelial carcinoma comprised $16 \%$ of 25 myoepithelial carcinomas of all histologic types in the largest series reported (49). My literature search finds an additional six cases, generally with poor follow-up (90, 88). Compared with the other two types of clear cell carcinomas discussed above, the clear cell myoepithelial carcinomas tend to have a more aggressive biologic behavior with a $50 \%$ recurrence rate and a $40 \%$ metastatic rate to lung and scalp. One of three cases in the series of Savera and colleagues died from disease with a mean time to death of 32 months although some with prolonged survivals have been documented (49).

\section{Myoepithelial Carcinomas}

Sheldon first used the term myoepithelioma in 1943 to describe noncancerous and cancerous (low grade invasive) salivary gland tumors composed of purely spindled smooth muscle-like or anastomosing proliferations of stellate cells (92). In 1977 Crissman reported the first case of malignant myoepi- 


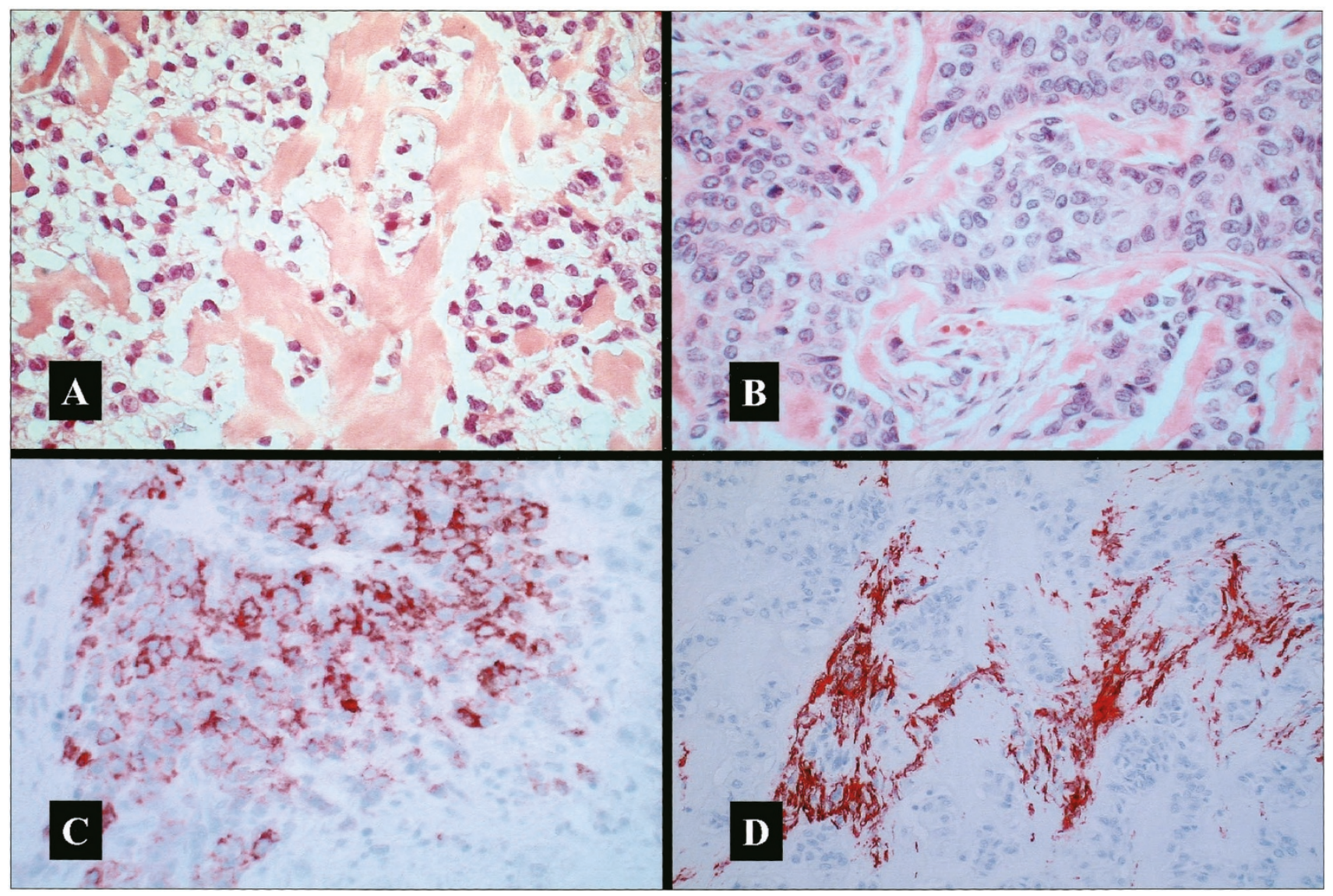

FIGURE 18. Hyalinizing clear cell carcinoma characterized by infiltrating cords of mildly atypical cells with clear (A) to eosinophilic (B) cytoplasm in a hyalinized stroma. Tumor cells stain for markers of epithelium like EMA (C) but lack myoepithelial differentiation with only the desmoplastic myofibroblastic stroma staining for muscle markers (D).

thelioma (spindle cell type) that metastasized to a regional lymph node (93). Many of these tumors have been unrecognized and called malignant mixed tumors or carcinomas arising out of mixed tumors. Less than 75 cases have been reported, most occurring in the major glands in adults. Roughly $40 \%$ have presented de novo and the rest have arisen out of pleomorphic adenomas or out of preexisting myoepitheliomas.

Grossly, myoepithelial carcinomas are mostly multinodular or diffuse infiltrative tumors. Microscopically, the periphery tends to be hypercellular with central necrosis or accumulation of myxoid matrix material.

We now recognize that the myoepithelial carcinomas comprise a broader histologic category than the originally reported spindle cell types. Histologically, there are no true glands formed although the epithelioid cell type may mimic adenocarcinoma by forming pseudoglands around myxoid ground substances. Usually more than one cell type composes an individual myoepithelial carcinoma (Fig. 21). It is most common to see the epithelioid cell type followed by clear cells, then the plasmacytoid variant followed by the spindle cell type (49). Most
$(60 \%)$ are of low cytologic grade. The clinical outcome of myoepithelial carcinoma is not predicted by the degree of cytologic atypia, number of mitoses or presence of necrosis. Chondroid metaplasia in a myoepithelial carcinoma may invoke the differential diagnosis of malignant mixed tumor because of the similarity to pleomorphic adenoma. Squamous and sebaceous metaplasia may also be encountered. The tumor-associated matrix is more often myxoid than hyalinized.

All of the malignant myoepithelial cell types are well defined by the nonspecific markers (S-100 protein, vimentin, high molecular weight cytokeratin). Of the more specific smooth muscle markers of myoepithelium, calponin is superior to muscle specific actin (HHF-35) and alpha smooth muscle actin but yet fails to stain half of the epithelioid cell type and $25 \%$ of the clear cell type (49). Therefore, to assure sensitivity of detection, it is best to approach this diagnosis with a panel of specific and nonspecific antibodies.

Because of the diverse histologic appearances, myoepithelial carcinomas may invoke a broad differential diagnosis. The fact that they often require a panel of antibodies to confirm myoepithelial dif- 


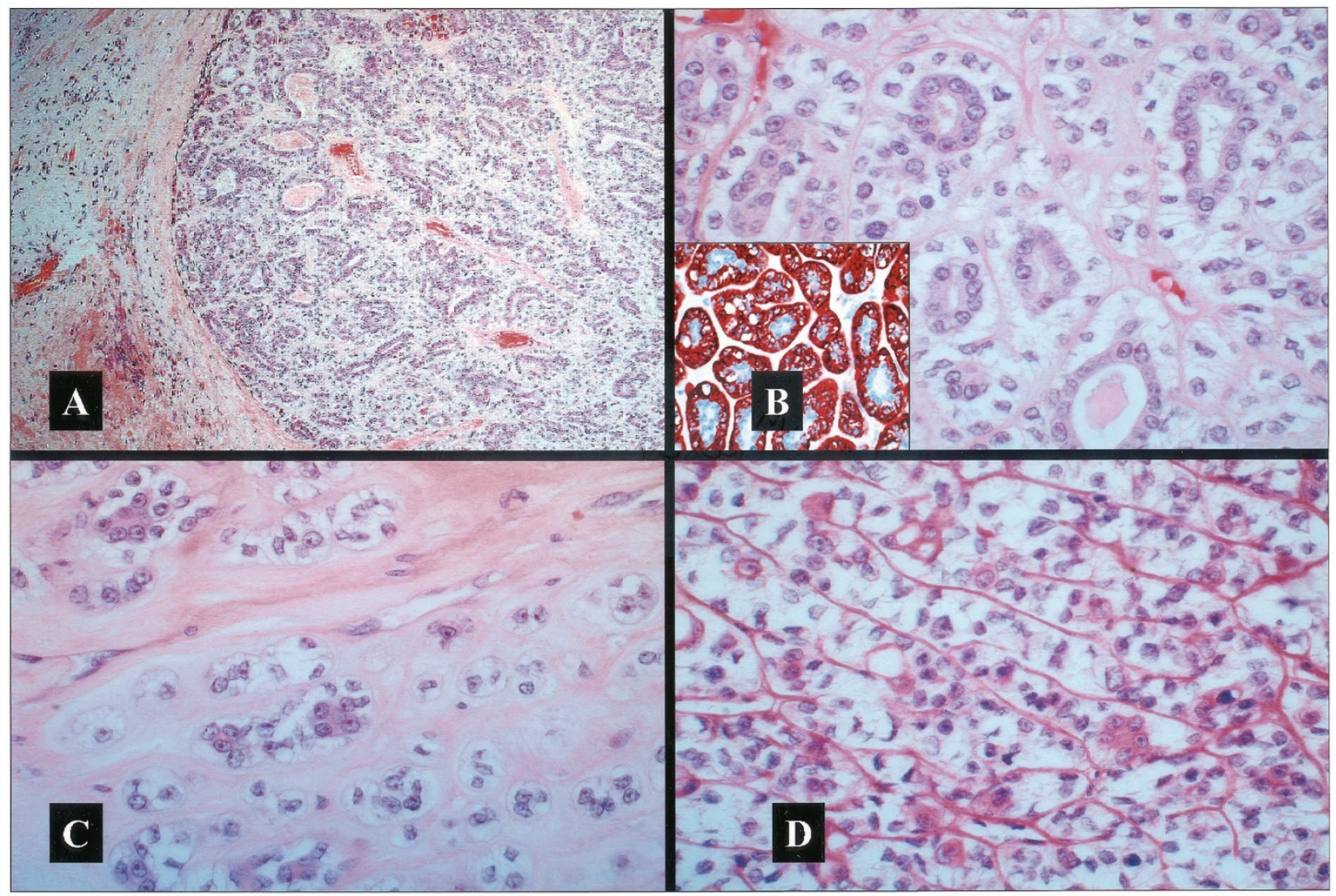

FIGURE 19. Epithelial-myoepithelial carcinomas usually have well circumscribed peripheral margins (A). Classic form is a double cell proliferation composed of a darker inner layer of ductal cells associated with a prominent outer layer of clear myoepithelial cells accentuated by immunostain for calponin (inset) (B). Variations include sclerotic (hyalinizing) (C) and clear cell dominant (ductal poor) (D) morphologies.

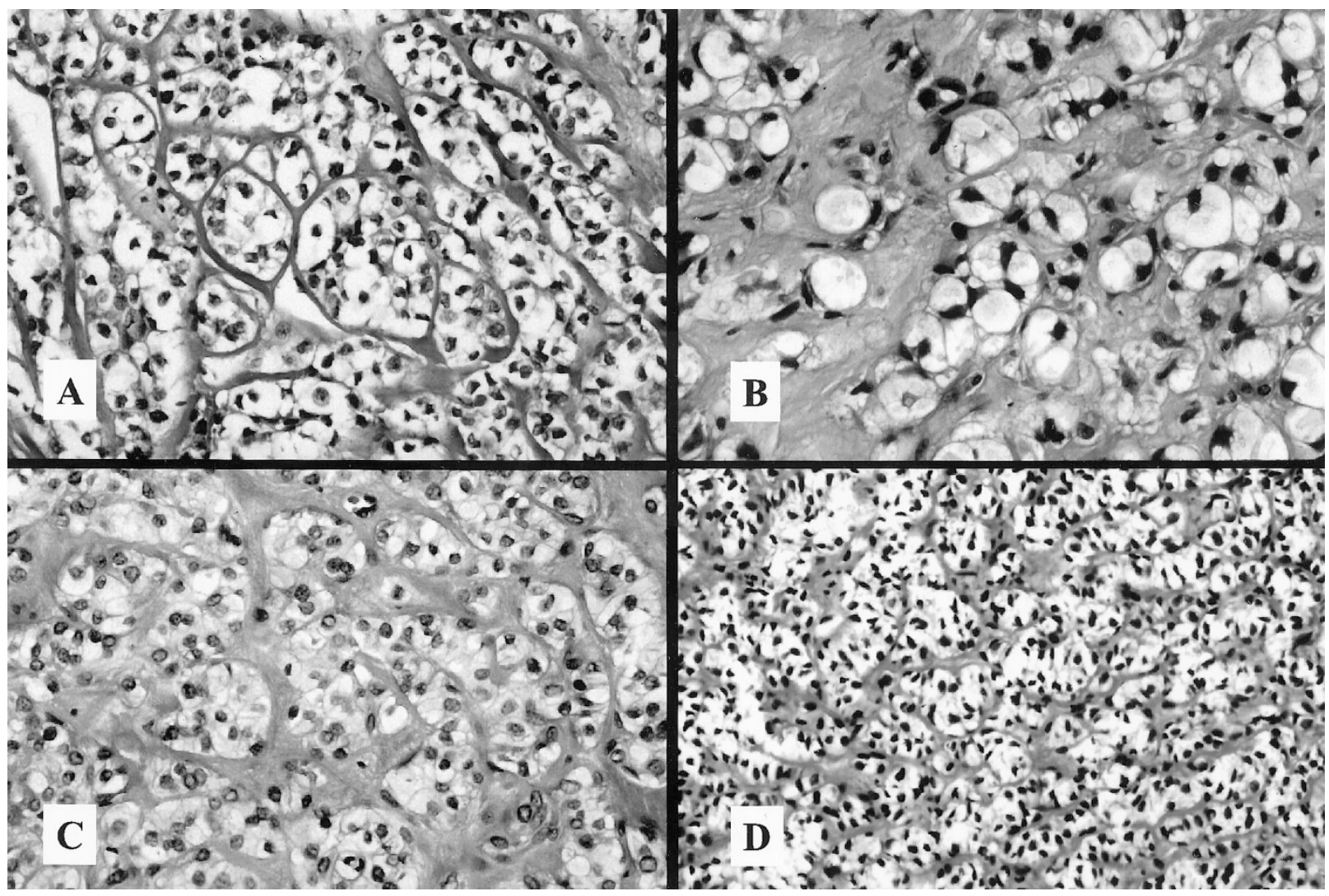

FIGURE 20. Clear cell myoepithelial carcinomas may exhibit various appearances with tight nests (A), vacuolated-signet ring-like cells (B), hyalinized nests (C), and trabecular (D) histologic patterns. (Cases provided courtesy of Dr. Adnan Savera.) 


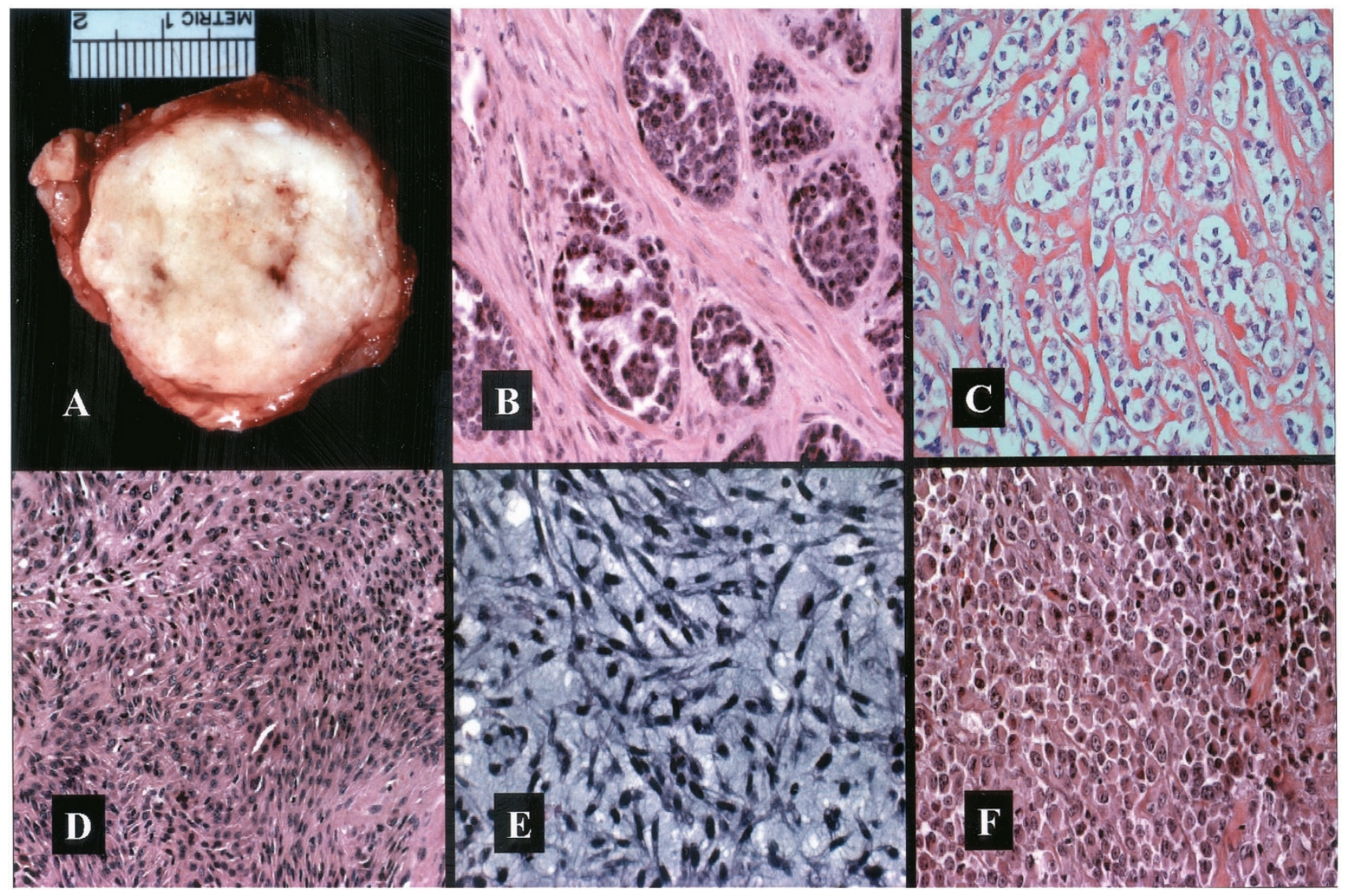

FIGURE 21. Myoepithelial carcinoma nodular tumor growth with central loose accumulation of myxoid matrix (A). Various histologic patterns include cells with epithelioid (B), clear (C), spindled (D), myxoid-stellate (E), and plasmacytoid (F) appearances. (Cases provided courtesy of Dr. Adnan Savera.)

ferentiation likely explains their infrequent diagnosis. The epithelioid cell type may mimic true salivary gland adenocarcinomas like PLGA, adenoid cystic carcinoma and adenocarcinoma (NOS). Lowgrade epithelioid myoepithelial carcinomas with their pseudolumens are distinguished by the absence of true tubules and the presence of myoepithelial immunomarkers (Fig. 22). Basaloid squamous cell carcinoma may be considered in the case of a high-grade epithelioid myoepithelial carcinoma with squamous metaplasia. Although basaloid squamous cell carcinoma may exhibit pseudoadenoid structures and replicated basement membrane, there is coexistent frank squamous cell carcinoma and often in situ carcinoma of the overlying mucosa.

The spindle cell variants of myoepithelial carcinoma may simulate true sarcomas like leiomyosarcoma, hemangiopericytoma, fibrosarcoma, and malignant peripheral nerve sheath tumor. However, these true sarcomas are negative or only focally cytokeratin positive although the smooth muscle neoplasms will share the myogenic immunoprofile of the myoepithelial carcinomas.

Although the plasmacytoid myoepithelial carcinomas may mimic true plasma cell neoplasms, they lack intracytoplasmic immunoglobulin light chains and are strongly cytokeratin and calponin positive (Fig. 22).

The differential diagnosis of the clear cell myoepithelial carcinomas has been discussed previously.

Myoepithelial carcinomas display a range of biologic behavior with $50 \%$ metastasizing to regional and distant sites and $35 \%$ of patients dying of disease (mean 32 months, range 2 months to 6 years) $(49,90,91)$. At this time the usual treatment modality is complete excision as the role of radiation therapy or chemotherapy is undefined.

\section{Salivary Duct Carcinoma}

Salivary duct carcinoma was identified in 1968 by Kleinsasser, Klein and Hubner as an uncommon, high-grade primary salivary gland malignancy resembling ductal carcinoma of breast (94). These cancers arise predominantly in the parotid gland (85\%) with few in the submaxillary gland and rarely intraorally. The usual demographic profile is that of adult males over 50 years of age. The aggressive biologic behavior of SDC is evident in rapid clinical growth and associated symptoms of facial nerve infiltration. 


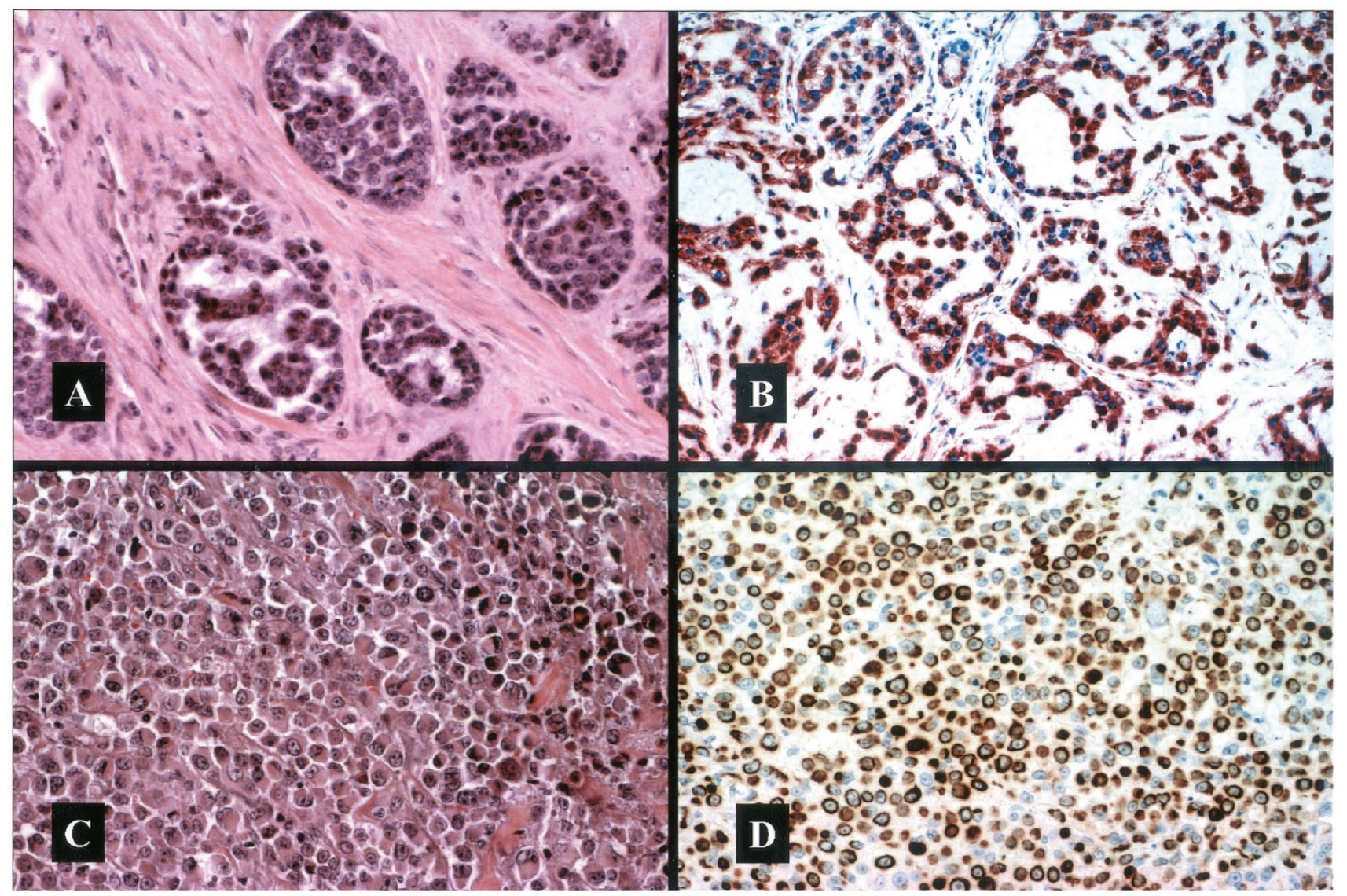

FIGURE 22. Myoepithelial carcinoma: epithelioid variant (A), pseudoglands stained for calponin (B); plasmacytoid variant (C), also stained for calponin (D). (Cases provided courtesy of Dr. Adnan Savera.)

Microscopically, these adenocarcinomas are similar to mammary ductal carcinomas. They demonstrate a hyalinized, fibrous stroma infiltrated by neoplastic ducts composed of solid, cribriform and papillary proliferations. There is often comedo necrosis and dystrophic calcifications may be present (Fig. 23). Cells are large with a range of cytologic atypia and may exhibit apocrine-like eosinophilic cytoplasm. Rarely, a myoepithelial layer associated with larger ducts can be visualized by light microscopy or enhanced with immunostains for muscle markers. This may represent precursor ductal carcinoma in situ or cancerization of native preexisting excretory ducts. Prognostically favorable pathologic observations include an intraductal component comprising greater than $90 \%$ of the tumor and smaller tumor size of less than 2-3 centimeters (95, 96). Discrimination from the rarely reported purely intraductal high grade carcinoma may require immunohistochemistry to clarify $(78,79)$.

The immunoprofile of SDC is quite interesting. Similar to breast cancers, it marks for GCDFP-15, oncogene her/2, progesterone receptor and occasionally estrogen receptor (97). Oddly, $58 \%$ of SDC also stain for prostatic acid phosphatase and $17 \%$ for prostate specific antigen. In addition, roughly
$90 \%$ of SDC bear androgen receptors by immunohistochemistry, which may prove to be a fruitful target for therapeutic hormonal intervention (98).

The rate of regional and distant metastasis is high $(50-60 \%)$ and $70 \%$ of patients in the MD Anderson series died from disease (95). Brandwein and colleagues' review of 58 cases demonstrated $55 \%$ of patients dead of disease within a mean of 29 months (96). Therefore, these cancers are treated aggressively with complete excision, radical neck dissection and postoperative radiation therapy.

\section{CONCLUSION}

This review has touched on practical clinical and diagnostic issues of the past 30 years in salivary gland tumor pathology. The next 30 years will see definition of the genetic and proteomic underpinnings of many of the morphologic and biologic distinctions we currently recognize. Hopefully, this will translate into more effective therapies for prevention, local control and cure for many of the salivary gland malignancies currently associated with notoriously protracted but lethal courses. 


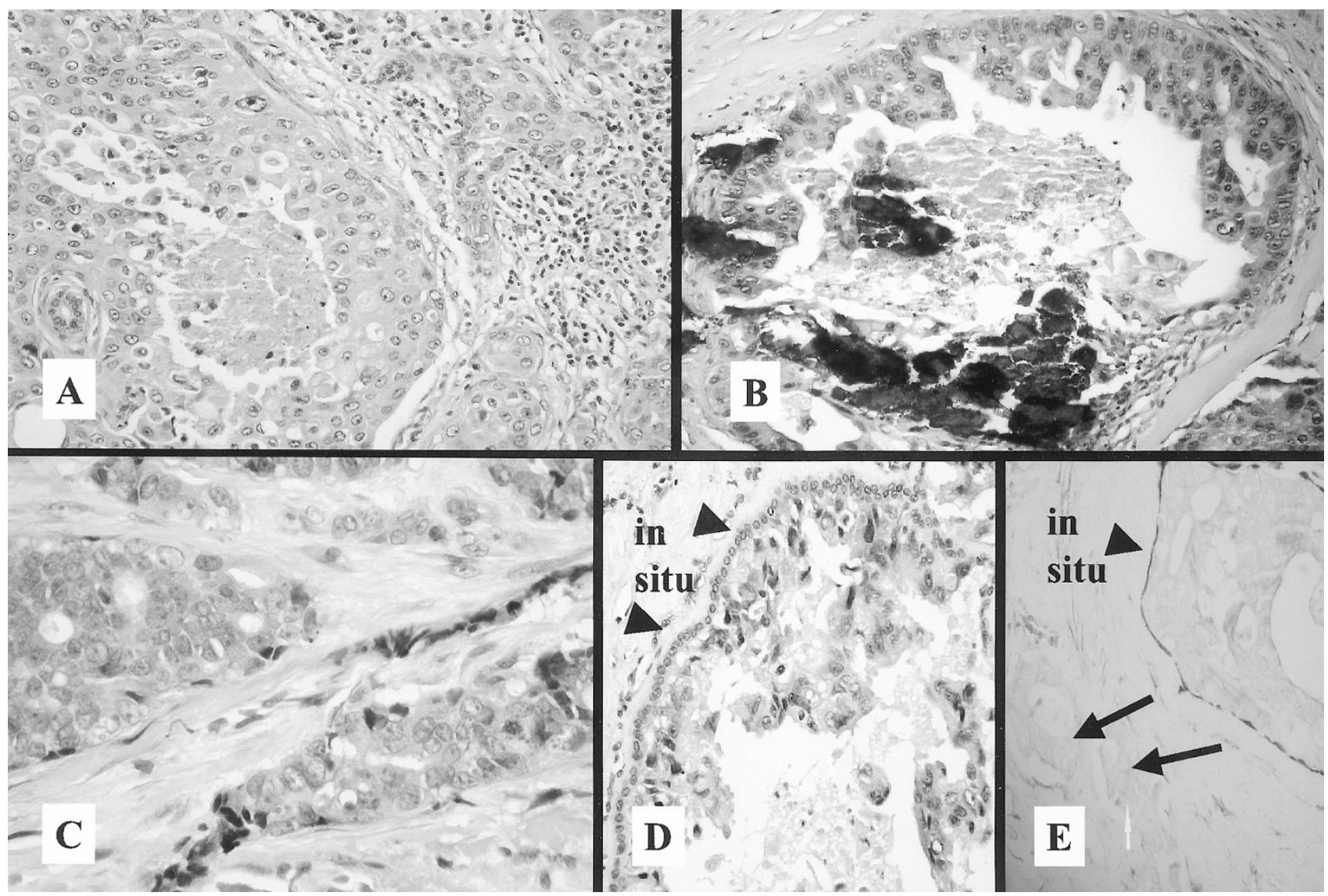

FIGURE 23. Salivary duct carcinoma is an invasive high grade adenocarcinoma with histologic features similar to ductal carcinomas of breast: solid and cribriform patterns composed of high grade nuclei with comedo necrosis (A) and dystrophic calcification (B); hyalinized and desmoplastic stromal invasion (C). Foci of intraductal growth with retained myoepithelium (D) are usually focal, representing either residual precursor ductal carcinoma in situ or cancerization of preexisting native ducts. The in situ (arrow head) and invasive (arrows) components can be clarified with stains for smooth muscle markers (E).

\section{REFERENCES}

1. Prasannan L, Pu A, Hoff P, Weatherly R, Castle V. Parotid carcinoma as a second malignancy after treatment of childhood acute lymphoblastic leukemia. J Pediatr Hematol Oncol 1999;21:535-8.

2. Modan B, Chetrit A, Alfandary E, Tamir A, Lusky A, Wolf M, et al. Increased risk of salivary gland tumors after low-dose irradiation. Laryngoscope 1998;108:1095-7.

3. Iezzoni JC, Gaffey MJ, Weiss LM. The role of Epstein-Barr virus in lymphoepithelioma-like carcinomas. Am J Clin Pathol 1995;103:308-15.

4. Raab-Traub N, Rajadurai P, Flynn K, Lanier AP. EpsteinBarr virus infection in carcinoma of salivary gland. J Virol 1991;65:7032-6.

5. Abbey LM, Schwab BH, Landau GC, Perkins ER. Incidence of second primary breast cancer among patients with a first primary salivary gland tumor. Cancer 1984;54:1439-42.

6. Sun EC, Curtis R, Melbye M, Goedert JJ. Salivary gland cancer in the United States. Cancer Epidemiol Biomarkers Prev 1999;8:1095-100.

7. Kotwall CA. Smoking as an etiologic factor in the development of Warthin's tumor of the parotid gland. Am J Surg 1992;164:646-7.

8. Chung YF, Khoo ML, Heng MK, Hong GS, Soo KC. Epidemiology of Warthin's tumor of the parotid gland in an Asian population. Br J Surg 1999;86:661-4.

9. Pinkston JA, Cole P. Cigarette smoking and Warthin's tumor. Am J Epidemiol 1996;144:183-7.
10. Swanson GM, Burns PB. Cancers of the salivary gland: workplace risks among women and men. Annu Epidemiol. 1997;7:369-74.

11. Headington JT, Batsakis JG, Beals TF, Campbell TE, Simmons JL, Stone WD. Membranous basal cell adenoma of parotid gland, dermal cylindromas and trichoepitheliomas. Comparative histochemistry and ultrastructure. Cancer 1977;39:2460-9.

12. Reingold IM, Keasbey LE, Graham JH. Multicentric dermaltype cylindromas of the parotid glands in a patient with florid turban tumor. Cancer 1977;40:1702-10.

13. Jungehulsing M, Wagner M, Damm M. Turban tumour with involvement of the parotid gland. J Laryngol Otol 1999;113: 779-83.

14. Depowski PL, Setzen G, Chui A, Koltai PJ, Dollar J, Ross JS. Familial occurrence of acinic cell carcinoma of the parotid gland. Arch Pathol Lab Med 1999;123:1118-20.

15. Merrick Y, Labeck H, Nielsen H, Hansen HS. Familial clustering of salivary gland carcinoma in Greenland. Cancer 1986;57:2097-102.

16. Autio-Harmainen H, Paakko P, Alavaikko M, Karvonen J, Leisti J. Familial occurrence of malignant lymphoepithelial lesion of the parotid gland in a Finnish family with dominantly inherited trichoepithelioma. Cancer 1988;61: 161-6.

17. Pinto AE, Fonseca I, Martins C, Soares J. Objective biologic parameters and their clinical relevance in assessing salivary gland neoplasms. Adv Anat Pathol 2000;7:294-306. 
18. Voz ML, Agten NS, Van de Ven WJM, Kas K. PLAG1, the main translocation target in pleomorphic adenoma of the salivary glands, is a positive regulator of IGF-II. Cancer Res 2000;60:106-13.

19. Hibbard MK, Kozakewich HP, Cin PD, Sciot R, Tan X, Xiao $\mathrm{S}$, et al. PLAG1 fusion oncogenes in lipoblastoma. Cancer Res 2000;60:4869-72.

20. Regezi JA, Batsakis JG. Histogenesis of salivary gland neoplasms. Otolaryngol Clin North Am 1977;10:297-307.

21. Batsakis JG. Salivary gland neoplasia: An outcome of modified morphogenesis and cytodifferentiation. Oral Surg 1980;49:229-32.

22. Dardick I, van Nostrand AWP, Phillips MJ. Histogenesis of salivary gland pleomorphic adenoma (mixed tumor) with an evaluation of the role of the myoepithelial cell. Hum Pathol 1982;13:62-75.

23. Foote FWJ, Frazell EL. Tumors of the major salivary glands. Atlas of Tumor Pathology, first series, Fascicle 11. Washington, DC: Armed Forces Institute of Pathology, 1954.

24. Ellis GL, Auclair PL. Tumors of the salivary glands. Atlas of Tumor Pathology, third series, Fascicle 11. Washington, DC: Armed Forces Institute of Pathology, 1996.

25. Vander Poorten VLM, Balm AJM, Hilgers FJM, Tan IB, Keus $\mathrm{RB}$, Hart AAM. Stage as major long term outcome predictor in minor salivary gland carcinoma. Cancer 2000;89:1195-204.

26. Gallo O, Frankchi A, Bottai GV, Fini-Storchi I, Tesi G, Boddi V. Risk factors for distant metastases from carcinoma of the parotid gland. Cancer 1997;80:844-51.

27. Fleming ID, Cooper JS, Henson DE, et al. (editors). American Joint Committee on Cancer: AJCC Cancer Staging Manual. Fifth ed. Philadelphia: Lippincott-Raven, 1997.

28. Spiro RH, Thaler HT, Hicks WF, Kher UA, Huvos AH, Strong EW. The importance of clinical staging of minor salivary gland carcinoma. Am J Surg 1991;162:330-6.

29. Szanto PA, Luna MA, Tortoledo ME, White RA. Histologic grading of adenoid cystic carcinoma of the salivary glands. Cancer 1984;54:1062-9.

30. Brandwein M, Ivanov K, Wallace D, Hille JJ, Wang B, Fahmy A, et al. Salivary mucoepidermoid carcinoma: A clinicopathologic study of 80 patients with special reference to histological grading. Am J Surg Pathol 2001;25:835-45.

31. Auclair P, Goode R, Ellis G. Mucoepidermoid carcinoma of intraoral salivary glands: evaluation and application of grading criteria in 143 cases. Cancer 1992;69:2021-30.

32. Goode RK, Auclair PL, Ellis GL. Mucoepidermoid carcinoma of the major salivary glands: clinical and histopathologic analysis of 234 cases with evaluation of grading criteria. Cancer 1998;82:1217-24.

33. Tortoledo ME, Luna MA, Batsakis JG. Carcinomas ex pleomorphic adenoma and malignant mixed tumors. Histomorphologic indexes. Arch Otolaryngol 1984;110:172-6.

34. Brandwein M, Huvos HG, Dardick I, Thomas MJ, Theise ND. Noninvasive and minimally invasive carcinoma ex mixed tumor: a clinicopathologic and ploidy study of 12 patients with major salivary tumors of low (or no?) malignant potential. Oral Surg Oral Med Oral Pathol 1996;81:655-64.

35. Auclair PL, Ellis GL. Atypical features in salivary gland mixed tumors: their relationship to malignant transformation. Mod Pathol 1996;9:652-7.

36. Stanley RJ, Weiland LH, Olsen KD, Pearson BW. Dedifferentiated acinic cell (acinous) carcinoma of the parotid gland. Otolaryngol Head Neck Surg. 1988;98:155-61.

37. Seifert G, Donath K. Hybrid tumours of salivary glands. Definition and classification of five rare cases. Eur J Cancer B Oral Oncol 1996;32B:251-9.

38. Henley JD, Seo IS, Dayan D, Gnepp DR. Sarcomatoid salivary duct carcinoma of the parotid gland. Hum Pathol 2000;31:208-13.
39. Love GL, Sarma DP. Spindle cell mucoepidermoid carcinoma of submandibular gland. J Surg Oncol 1986;31:66-8.

40. Cheuk W, Chan JKC, Ngan RKC. Dedifferentiation in adenoid cystic carcinoma of salivary gland. An uncommon complication associated with an accelerated clinical course. Am J Surg Pathol 1999;23:465-72.

41. Pelkey TJ, Mills SE. Histologic transformation of polymorphous low-grade adenocarcinoma of salivary gland. Am J Clin Pathol 1999;111:785-91.

42. Alos L, Carrillo R, Ramos J, Baez C, Mallofre C, Fernandez A, Cardes A. High-grade carcinoma component in epithelialmyoepithelial carcinoma of salivary glands. Clinicopathological, immunohistochemical and flow-cytometric study of three cases. Virch Archiv 1999;434:291-9.

43. Zarbo RJ, Regezi JA, Batsakis JG. S-100 protein in salivary gland tumors: an immunohistochemical study of 129 cases. Head Neck Surg 1986;8:268-75.

44. Zarbo RJ, Hatfield JS, Trojanowski JQ, Crissman JD, Regezi JA, Maisel $\mathrm{H}$, et al. Immunoreactive glial fibrillary acidic protein in normal and neoplastic salivary glands: a combined immunohistochemical and immunoblot study. Surg Pathol 1988;1:55-63.

45. Zarbo RJ, Bacchi CE, Gown AM. Muscle-specific protein expression in normal salivary glands and pleomorphic adenomas: an immunocytochemical study with biochemical confirmation. Mod Pathol. 1991;4:621-6.

46. Zarbo RJ, Prasad AR, Regezi JA, Gown AM, Savera AT. Salivary gland basal cell and canalicular adenomas. Immunohistochemical demonstration of myoepithelial cell participation and morphogenetic considerations. Arch Pathol Lab Med 2000;124:401-5.

47. Savera AT, Gown AM, Zarbo RJ. Immunolocalization of three novel smooth muscle-specific proteins in salivary gland pleomorphic adenoma: Assessment of the morphogenetic role of myoepithelium. Mod Pathol 1997;10:1093-100.

48. Prasad AR, Savera AT, Gown AM, Zarbo RJ. The myoepithelial immunophenotype in 135 benign and malignant salivary gland tumors other than pleomorphic adenoma. Arch Pathol Lab Med 1999;123:801-6.

49. Savera AT, Sloman A, Huvos AG, Klimstra DS. Myoepithelial carcinoma of the salivary glands. A clinicopathologic study of 25 patients. Am J Surg Pathol 2000;24:761-74.

50. Prasad AR, Savera AT, Regezi JA, Zarbo RJ. Antimitochondrial antibody - a diagnostic discriminant of salivary gland oncocytic tumors and acinic cell carcinomas [Abstract]. Mod Pathol 1999;12:130A.

51. De Araujo VC, de Sousa SOM, Carvalho YR, de Araujo NS. Application of immunohistochemistry to the diagnosis of salivary gland tumors. Appl Immunohisto Molec Morphol 2000;8:195-202.

52. Barbareschi M, Pecciarini L, Cangi MG, Macri E, Rizzo A, Viale G, et al. p63, a p53 analogue, is a selective myoepithelial nuclear marker in human breast tissue and neoplasms [Abstract]. Mod Pathol 2001;14:21A.

53. Foschini MP, Scarpellini F, Gown AM, Eusebi V. Differential expression of myoepithelial markers in salivary, sweat and mammary glands. Int J Surg Pathol 2000;8:29-37.

54. Sternlicht MD, Safarians S, Rivera SP, Barsky SH. Characterizations of the extracellular matrix and proteinase inhibitor content of human myoepithelial tumors. Lab Invest 1996;74:781-96.

55. Sternlicht MD, Barsky SH. The myoepithelial defense: a host defense against cancer. Med Hypoth 1997;48:37-46.

56. Lee P-S, Sabbath-Solitare, Redondo TC, Ongcapin EH. Molecular evidence that the stromal and epithelial cells in pleomorphic adenomas of salivary gland arise from the same origin: clonal analysis using human androgen receptor gene (HUMARA) assay. Hum Pathol 2000;31:498-503. 
57. Kleinsasser O, Klein HJ. Basalzelladenome der speicheldrusen. Arch Klin Exper Ohren Nasen und Kehlkopfheilk 1967;189:302-16.

58. Seifert G, Sobin LH. Histological typing of salivary gland tumors. World Health Organization international histological classification of tumours. 2nd ed. New York: SpringerVerlag, 1991.

59. Nagao T, Sugano I, Ishida Y, Matsuzaki M, Konno A, Kondo $\mathrm{Y}$, et al. Carcinoma in basal cell adenoma of the parotid gland. Path Res Pract 1997;193:171-8.

60. Dardick I, Daley T, van Nostrand AW. Basal cell adenoma with myoepithelial cell-derived "stroma": a new major salivary gland tumor entity. Head Neck Surg 1986;8:257-67.

61. Batsakis JG, Brannon RB, Sciubba JJ. Monomorphic adenomas of major salivary glands: a study of 96 tumors. Clin Otolaryngol 1981;6:129-43.

62. Luna MA, Tortoledo MME, Allen M. Salivary dermal analogue tumors arising in lymph nodes. Cancer 1987;59:1165-9.

63. Zarbo RJ, Ricci Jr A, Kowalczyk PD, Cartun RW, Knibbs DR. Intranasal dermal analogue tumor (membranous basal cell carcinoma). Ultrastructure and immunohistochemistry. Arch Otolaryngol 1985;111:333-7.

64. Batsakis JG, Luna MA, el-Naggar AK. Basaloid monomorphic adenomas. Annu Otol Rhino Laryngol 1991;100:68790.

65. Daley TD. The canalicular adenoma: considerations on differential diagnosis and treatment. J Oral Maxillofac Surg. 1984;42:728-30.

66. Ellis GL, Wiscovitch JG. Basal cell adenocarcinomas of the major salivary glands. Oral Surg Oral Med Oral Pathol 1990 69:461-9.

67. Muller S, Barnes L. Basal cell adenocarcinoma of the salivary glands. Report of seven cases and review of the literature. Cancer 1996;78:2471-7.

68. Evans HL, Batsakis JG. Polymorphous low-grade adenocarcinoma of minor salivary glands. A study of 14 cases of a distinctive neoplasm. Cancer 1984;53:935-42.

69. Freedman PD, Lumerman H. Lobular carcinoma of intraoral minor salivary gland origin. Report of twelve cases. Oral Surg Oral Med Oral Pathol 1983;56:157-65.

70. Batsakis JG, Pinkston GR, Luna MA, Byers RM, Sciubba JJ, Tillery GW. Adenocarcinoma of the oral cavity: A clinicopathologic studyof terminal duct carcinomas. J Laryngol Otol 1983;97:825-35.

71. Wenig BM, Harpaz N, Del Bridge C. Polymorphous lowgrade adenocarcinoma of seromucous glands of the nasopharynx: a report of a case and a discussion of the morphologic and immunohistochemical features. Am J Clin Pathol 1989;92:104-9.

72. Castle JT, Thompson LDR, Frommelt RA, Wenig BM, Kessler HP. Polymorphous low grade adenocarcinoma. A clinicopathologic study of 164 cases. Cancer 1999;86:207-19.

73. Regezi JA, Zarbo RJ, Stewart JC, Courtney RM. Polymorphous low-grade adenocarcinoma of minor salivary gland a comparative histologic and immunohistochemical study. Oral Surg Oral Med Oral Pathol 1991;71:469-75.

74. Mills SE, Garland TA, Allen MSJ. Low-grade papillary adenocarcinoma of palatal salivary gland origin. Am J Surg Pathol 1984;8:367-74.

75. Slootweg PJ, Muller H. Low-grade adenocarcinoma of the oral cavity. A comparison between the terminal duct and the papillary type. J Cranio-Max Fac Surg 1987;15:359-64.

76. Vincent SD, Hammond HL, Finkelstein MW. Clinical and therapeutic features of polymorphous low-grade adenocarcinoma. Oral Surg Oral Med Oral Pathol 1994;77:41-7.

77. Delgado R, Klimstra D, Albores-Saavedra J. Low grade salivary duct carcinoma. A distinctive variant with a low grade histology and a predominant intraductal growth pattern. Cancer 1996;78:958-67.
78. Anderson C, Muller R, Piorkowski R, Knibbs DR, Vignotti P. Intraductal carcinoma of major salivary gland. Cancer 1992; 69:609-14.

79. Chen KTK. Intraductal carcinoma of the minor salivary gland. J Laryngol Otol 1983;97:189-91.

80. Dardick I. Miscellaneous carcinomas. Salivary Gland Tumor Pathology New York: Igaku-Shoin; 1996. p. 239-43.

81. Batsakis JG. Clear cell tumors of salivary glands. Annu Otol 1980;89:196-7.

82. Milchgrub S, Gnepp DR, Vuitch F, Delgado R, AlboresSaavedra J. Hyalinizing clear cell carcinoma of salivary gland. Am J Surg Pathol 1994;181:74-82.

83. Tang SK, Wan SK, Chan JKC: Hyalinizing clear cell carcinoma of the salivary gland: report of a case with multiple recurrences over 12 years. Am J Surg Pathol 1995;19:240-1.

84. Berho M, Huvos AG: Central hyalinizing clear cell carcinoma of the mandible and the maxilla: a clinicopathologic study of two cases with an analysis of the literature. Hum Pathol 1999;30:101-5.

85. Simpson RHW, Sarsfield PT, Clarke T, Babajews AV: Clear cell carcinoma of minor salivary glands. Histopathology 1990;17:433-8.

86. Donath K, Seifert G, Schmitz R. Diagnose und ultrastruktur des tubularen speichelgangcarcinoms. Epithelialmyoepitheliales schaltstustuckcarcinoma. Virch Arch A. 1972;356:16-31.

87. Simpson RHW, Clarke TJ, Sarsfield PTL, Gluckman PGC. Epithelial-myoepithelial carcinoma of salivary glands. J Clin Pathol 1991;44:419-23.

88. Luna MA, Ordonez NG, Mackay B, Batsakis JG, Guillamondegui O. Salivary epithelial-myoepithelial carcinomas of intercalated ducts: a clinical, electron microscopy and immunocytochemical study. Oral Surg Oral Med Oral Pathol 1985;59:482-90.

89. Fonseca I, Soares J. Epithelial-myoepithelial carcinoma of the salivary glands. A study of 22 cases. Virch Arch A Pathol Anat 1993;422:389-96.

90. Michal A, Skalova A, Simpson RHW, Rychterova V, Leivo I. Clear cell malignant myoepithelioma of the salivary glands. Histopathol 1996;28:309-15.

91. Ogawa I, Nikai H, Takata T, Ijuhin N, Miyauchi M, Ito H, et al. Clear cell tumors of minor salivary gland origin. Oral Surg Oral Med Oral Pathol 1991;72:200-7.

92. Sheldon WH. So-called mixed tumors of the salivary glands. Arch Pathol 1943;35:1-20.

93. Crissman JD, Wirman JA, Harris A. Malignant myoepithelioma of the parotid gland. Cancer 1977;40:3042-9.

94. Kleinsasser O, Klein HJ, Hubner G. Salivary duct carcinoma: a group of salivary gland tumors analogous to mammary duct carcinoma. Arch Klin Exper Ohren 1968; 192:100-15.

95. Hui KK, Batsakis JG, Luna MA, Mackay B, Byers RM. Salivary duct carcinoma: a high grade malignancy. J Laryngol Otol 1986;100:105-14.

96. Brandwein MS, Jagirdar J, Patil J, Biller H, Kaneko M. Salivary duct carcinoma (cribriform salivary carcinoma of excretory ducts). Cancer 1990;65:2307-14.

97. Wick MR, Ockner DM, Mills SE, Ritter JH, Swanson PE. Homologous carcinomas of the breasts, skin and salivary glands. A histologic and immunohistochemical comparison of ductal mammary carcinoma, ductal sweat gland carcinoma, and salivary duct carcinoma. Am J Clin Pathol 1998; 109:75-84.

98. Fan C-Y, Wang J, Barnes EL. Expression of androgen receptor and prostatic specific markers in salivary duct carcinoma. An immunohistochemical analysis of 13 cases and review of the literature. Am J Surg Pathol $2000 ; 24: 579-86$ 
99. Gerughty RM, Hennigar GR, Brown RM. Adenosquamous carcinoma of the nasal, oral and laryngeal cavities: A clinicopathologic survey of ten cases. Cancer 1968;22:1140-55.

100. Abrams AM, Finck FM. Sialadenoma papilliferum. A previously unreported salivary gland tumor. Cancer 1969;24:1057-63.

101. Abbey LM. Solitary intraductal papilloma of the minor salivary glands. Oral Surg Oral Med Oral Pathol 1975;40:135-40.

102. White DK, Miller AS, McDaniel RK, Rothman BN. Inverted ductal papilloma: A distinctive lesion of minor salivary gland. Cancer 1982;49:519-24.

103. Nagao K, Matsuzaki O, Saiga H. Histopathologic studies of undifferentiated carcinoma of the parotid gland. Cancer 1982;50:1572-9.
104. Taylor GP. Congenital epithelial tumor of the parotid gland-sialoblastoma. Pediatr Pathol 1988;8:447-52.

105. Ellis GL. "Clear cell" oncocytoma of salivary gland. Hum Pathol 1988;19:862-7.

106. Hui KK, Luna MA, Batsakis JG, Ordonez NG, Weber R. Undifferentiated carcinomas of the major salivary glands. Oral Surg Oral Med Oral Pathol 1990;69:76-83.

107. Dehner LP, Valbuena L, Perez-Atayde A, Reddick RL, Askin FB, Rosai J. Salivary gland anlage tumor ("congenital pleomorphic adenoma”): A clinicopathologic, immunohistochemical and ultrastructural study of nine cases. Am J Surg Pathol 1994;18:25-36. 